This PDF is a selection from a published volume from the National Bureau of Economic Research

Volume Title: African Successes, Volume II: Human Capital

Volume Author/Editor: Sebastian Edwards, Simon Johnson, and David N. Weil, editors

Volume Publisher: University of Chicago Press

Volume ISBNs: 978-0-226-31605-5 (cloth)

Volume URL: http://www.nber.org/books/afri14-2

Conference Dates: December 11-12, 2009; July 18-20, 2010; August 3-5, 2011

Publication Date: September 2016

Chapter Title: Family Ties, Inheritance Rights, and Successful Poverty Alleviation: Evidence from Ghana

Chapter Author(s): Edward Kutsoati, Randall Morck

Chapter URL: http://www.nber.org/chapters/c13378

Chapter pages in book: (p. $215-252$ ) 


\title{
Family Ties, Inheritance Rights, and Successful Poverty Alleviation Evidence from Ghana
}

\author{
Edward Kutsoati and Randall Morck
}

\subsection{Introduction}

In much of sub-Saharan Africa, the idea of a family extends beyond its conjugal members. A lineage, or extended family, is a far larger web of relationships in which all members have a common ancestor, either male or female. One's relationship with members of one's extended family may be as important as, and in some cases more important than, one's relationship with one's spouses and children. Historically, lineages are bastions of emotional and financial support (Plateau 1991). Lineages can pay for education and training, and their social safety nets can support risk taking and entrepreneurship. However, expectations of being supported by, and of having to support, members of one's lineage can also deter human capital

Edward Kutsoati is associate professor of economics at Tufts University. Randall Morck holds the Stephen A. Jarislowsky Distinguished Chair in Finance in the School of Business at the University of Alberta and is a research associate of the National Bureau of Economic Research.

We are deeply grateful to Kofi Awusabo-Asare for coordinating our household survey and his numerous suggestions along the way. We are also grateful to the management of the Social Security and National Insurance Trust (SSNIT) Fund of Ghana for providing access to individual records; the team of research assistants, Yvonne Adjakloe, Eugene Darteh, and Kobina Esia-Donkoh for their superb field work; William Angko and Alex Larbie-Mensah for the painful task of collecting the SSNIT data; and Greatjoy Ndlovu and Panos Rigopoulos for excellent assistance with the data analysis. We thank participants at the National Bureau of Economic Research (NBER)/Africa Project meetings in Cambridge and Zanzibar for their comments and gratefully acknowledge financial support from the NBER and the SSHRC. The views expressed here, however, are solely ours and do not reflect those of the NBER or the SSNIT. For acknowledgments, sources of research support, and disclosure of the authors' material financial relationships, if any, please see http://www.nber.org/chapters/c13378.ack. 
accumulation, labor supply, entrepreneurship, and risk taking. ${ }^{1}$ The actual importance of extended families in any given context is thus an empirical question.

This study explores how inheritance rules in two distinct Ghanaian systems of defining extended family membership interact with formal legal inheritance rules to affect asset accumulation during marriage and the economic situations of widows and their children. Until 1985, intestate inheritances were determined by traditional custom, and this depended on how one's extended family was defined. People whose tribal customs are matrilineal define their lineages through their female bloodlines only: their mothers and maternal cousins, aunts, uncles, grandparents, and so on are their blood kin, but their fathers and paternal cousins, aunts, uncles, grandparents, and so on are not. People whose tribal customs are patrilineal analogously define blood kinship as flowing through their paternal, but not maternal, bloodlines. Under matrilineal lineage norms a man's children are thus not his blood kin, and his heir should he die intestate (without a legal will) is his sister's son, his nearest blood relative in the next generation. Under patrilineal norms his estate devolves to his children, who are considered his blood kin. Under both traditional norms widows have no inheritance rights, and are often left with no assets because of a traditional presumption that assets acquired during marriage belong to the husband. Rather than relying on their husbands' estates, they must depend on their lineages' social safety nets.

The 1985 Intestate Succession (PNDC) Law 111 was enacted to alter perceived adverse effects of these traditional norms, especially on widows with husbands of matrilineal lineage. Our surveys of widows living in villages selected for matrilineal, patrilineal, or mixed-lineage norms reveal that a quarter of a century later, Law 111 is little used and traditional inheritance norms persist. This confirms previous work (FIDA 2007; Fenrich and Higgins 2005; Scholz and Gomez 2004). We link this to a dearth of information about the formal law, lack of access to the formal judicial system, and the continued social importance of overtly adhering to traditional norms. Most low-income Ghanaians die intestate, and while some profess to know of Law 111, remarkably few make use of it. Those who know of the law have, however, built up more family assets jointly, even after controlling education level. This effect is, however, least evident for widows with husbands from matrilineal lineage traditions - the very people the reforms focused on advancing.

1. African extended families are attracting new attention in both the theoretical and empirical economics literatures. Bertrand, Mullainathan, and Miller (2003) find older relatives becoming eligible for pension payments affect adult labor supply decisions in black South African homes. Chiteji and Hamilton (2002) find transfers from richer to poorer members of African American families deter wealth accumulation more than in white families. Hoff and Sen (2006) model extended families becoming poverty traps, and Alger and Weibull $(2008,2010)$ show that the expectation of financial assistance from family members can prevent the development of insurance markets. 
We also survey widows about the extent of support from their lineages, and their access to economic (money, education, and health care) and social support. Widows who acknowledge closer ties with members of either their own or their spouse's lineage report more support, as do those very few who made use of Law 111 or who inherited via a legal will. Intriguingly, widows of matrilineal lineage also report better economic support, consistent with maternal lineage social safety nets being more effective.

Our survey targets widows living in villages, and not connected to the formal sector of the economy. While these are most representative, the inheritance practices of people in the formal sector are also of interest. Due to the low survey response rates from middle- and high-income families, we therefore complement our survey analysis with individual-level data from the Social Security and National Insurance Trust (SSNIT), the sole pension annuity program for retirees. This program provides retirees with fixed pension annuities and should they die before the annuity expiration dates, survivor benefits are payable to selected heir(s). In a second attempt to improve the economic situations of widows and their children, the 1998 Children Act 560 mandates that 60 percent of this survivor benefit pass to the decedent's children under age eighteen, with the decedent's choice of beneficiaries governing only the disposition of the remaining 40 percent.

Due to confidentiality rules, the SSNIT allowed access only to older files. Despite this working against finding significant effects, the data provide some evidence that Act 560 benefits the nuclear families of decedents, especially those of matrilineal lineage.

Together these results indicate that these formal legal reforms have a very limited impact on most Ghanaians. Specifically, they are efficacious only for people connected to the formal economy. For most Ghanaians, living in villages and dependent on the traditional economy, the reforms are either irrelevant or of only indirect help.

Our study complements a growing empirical literature on the economics of the family, and on the importance of inheritance rights in developing countries. Quisumbing and Ostuka (2001) link land inheritance rights to skills acquisition decisions in Sumatra; Quisumbing et al. (2001) report that improved women's land rights in Ghana incentivize the cultivation of tree crops, such as cocoa. Lastarria-Cornhiel (1997) link privatization to the land rights of marginalized Africans. Hacker (2010) provides a broad literature review, and discusses gender-related inheritance issues in different parts of the world. Ellul, Pagano and Panunzi (2010), in a sample of 10,004 family and nonfamily businesses across thirty-eight countries, find that strict (traditional) inheritance laws interact with weak investor protection laws to impede investment in family businesses, but not in nonfamily businesses. Where inheritance norms allow (or require) business owners to bequeath more substantial proportions of their estates to noncontrolling heirs, investors are more reluctant to provide external capital. 
The chapter is organized as follows: section 7.2 provides a brief background on traditional inheritance rules in matrilineal and patrilineal lineages. Section 7.3 outlines the relevant features of Law 111 and Act 560. Section 7.4 describes our data, and section 7.5 summarizes our econometric methodology and empirical results. Section 7.6 concludes.

\subsection{Traditional Inheritance Rules: A Background}

The inheritance rights of spouses and children depend on the form of their marriage and on their lineage traditions. Marriages in Ghana can be monogynous or polygynous, and can be ordinance marriages (legally valid civil or Christian marriages) or customary marriages as prescribed by customary tribal traditions. ${ }^{2}$ The last is by far the most popular, with up to 80 percent of marriages in contemporary Ghana entered solely under the customary system (Awusabo-Asare 1990).

In practice, almost all couples marry in a traditional ceremony recognizing the new bond between the two families. Subsequently, some follow up with an ordinance marriage in a church. These are usually wealthier couples. Not all traditional marriages can be recapitulated as ordinance marriages because traditional marriages can be polygynous, while ordinance marriages cannot. While the ordinance marriage may specify inheritance rules - for example, that equal thirds might go to the decedent's spouse, children, and extended family - customary rules take precedence in marriages that are also entered in traditional ceremonies.

Under customary rules, the corpse and all property of a person who dies without having written a will (an intestate decedent) passes to the family. One's family is customarily defined as one's lineage: "the extended group of lineal descent of a common ancestor or ancestress" (Kludze 1983, 60). The head of the lineage appoints a "successor" to assume the estate, rights, and obligations of the decedent on behalf of the lineage. Only a legal will overrides customary law, and few Ghanaians have legal wills. The applicable customary law varies across ethnic groups, and each tribal tradition is an intricate body of rules, obligations, and norms. However, Ghana's customary legal regimes as regards inheritances can be meaningfully divided into two broad categories: matrilineal and patrilineal traditions.

2. Islamic marriage has a "special" status, with the Quran defining marriage and inheritance rules. These let a man marry up to four women, let only men inherit certain assets, and so forth. Islamic law shapes the customary traditions of Muslim tribes, which predominate in the far north. Consensual unions, with neither an ordinance marriage nor a marriage under tribal custom, provide no inheritance rights whatsoever. Deceased common-law spouses' property reverts to their families. Intervivos transfers to a common-law spouse are subject to legal challenge. 


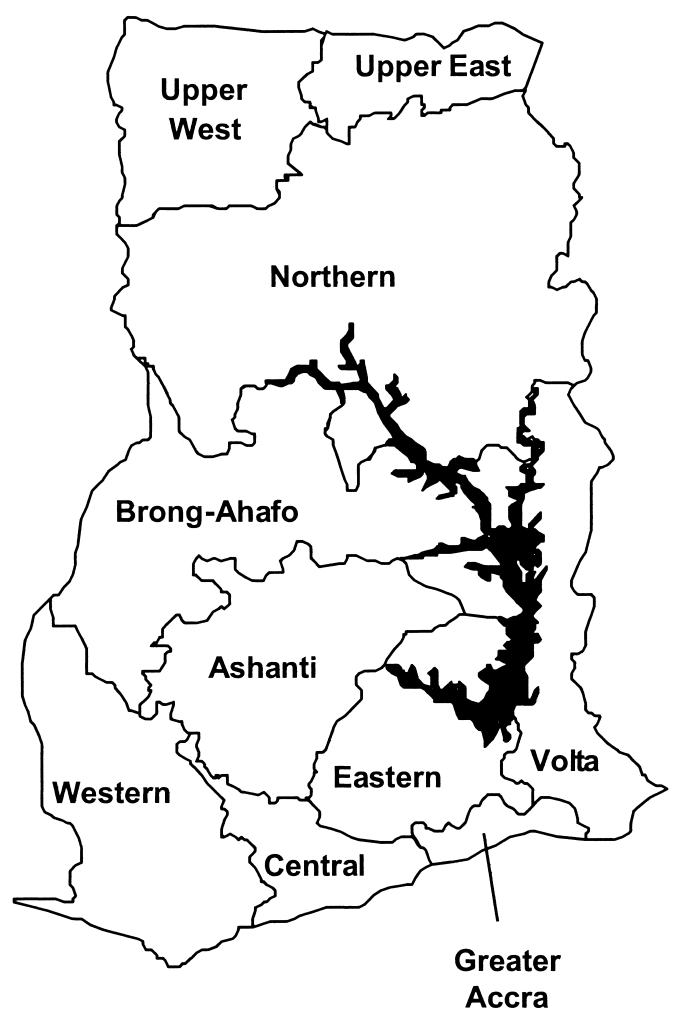

Fig. 7.1 Regional map of Ghana depicting the ten regions

Note: The matrilineal societies are found in the southwest regions (Ashanti, Central, and Western) and parts of the Northern region. Patrilineal groups are in the southeastern (Greater Accra and Volta) and the Upper regions.

\subsubsection{Matrilineal Customary Inheritance Norms}

The Akans (Ashanti, Central, and Western regions) and the Lobi, Tampolese, and Baga (Northern Ghana) all use variants of matrilineal customary law. The Akans, constituting about 48 percent of Ghana's population and the largest tribe, ${ }^{3}$ are often considered an archetypical matrilineal culture. Under matrilineal tradition, a family's controlling spirit passes from generation to generation only through female blood lines, from whom Akan children are believed to inherit their "flesh and blood," that is, their source

3. The Akan tribe contains subgroups defined by their mostly mutually intelligible dialects. The largest groups are the Asante, Akuapem Twi, Akyem, Brong (in the Brong-Ahafo region), Fante, and Agona. 
of existence (Bleeker 1966). Family ties, traced only through female ancestors, define one's extended family, lineage, or matriclan. ${ }^{4}$

In a matrilineal tribe, one is thus related by blood to one's mother, full siblings, and half siblings by a common mother (uterine half siblings), but not to one's father nor to any half siblings by a common father. Thus, children belong to their mother's lineage, but not the father's. A traditional Akan male thus feels blood kinship to his mother's brother (wəfa: pron. wo- $f a$ ), but at most a weak connection to his father's brother.

An Akan male does not consider his children to be his blood kin. His closest blood relative in the next generation is his sister's son, and this maternal nephew (wofase: pron. wa-fa-si) is his presumed heir if his brothers predecease him and he dies intestate. Because Akan traditional rules revert a married couple's acquired property to the decedent's matrilineal extended family (Awusabo-Asare 1990), a widow and her children can be left destitute by the husband's death. She must thus look to her brothers for support, and her children must look to their maternal uncles for bequests. The expectation of inheriting a maternal uncle's wealth is often said to blunt an Akan nephew's incentives to acquire human capital or seek a job, and is captured neatly in an old Akan adage wofa wsho nti me nye egyu ma (lit. "I have a rich uncle; I don't need a job").

Note that a matrilineal definition of who is, and is not, in one's family does not imply a matriarchal power structure over that family. Chiefs and tribal leaders in matrilineal tribes are almost always male, and the leaders of matrilineally defined extended families are almost always their highest status males. ${ }^{5}$

Figure 7.2 illustrates how a matrilineal controlling spirit flows from generation to generation. The members of a matriclan all share a common female ancestor, to whom their mothers are tied by female-to-female lines of descent (shown in black).

\subsubsection{Patrilineal Customary Inheritance Norms}

The main patrilineal societies in Ghana are the Ga tribe (in the Greater Accra region), the Ewe tribe (in the Volta region), and the Dagomba and Nanumba tribes in the Upper East region. In a patrilineal tribe, a family's controlling spirit passes from generation to generation only through male blood lines, and these connections define one's extended family, or patriclan. ${ }^{6}$

Under patrilineal custom, one's extended family thus includes one's chil-

4. One's matriclan is precisely those with whom one shares identical mitochondrial DNA.

5. Matrilineal definitions of ethnicity are not unknown in the West. For example, one is Jewish by birth only if one's mother is Jewish. A Jewish father does not count. As with the Akan, a matrilineal definition of family did not imply matriarchal control of ancient Hebrew tribes or kingdoms. Many American aboriginal cultures also use a matrilineal definition of blood kinship - the Cherokee, Gitksan, Haida, Hopi, Iroquois, Lenape, and Navajo, among others.

6. One's patrician is precisely male relatives with $\mathrm{Y}$ chromosomes identical to that of one's father, plus their immediate children of both genders. 


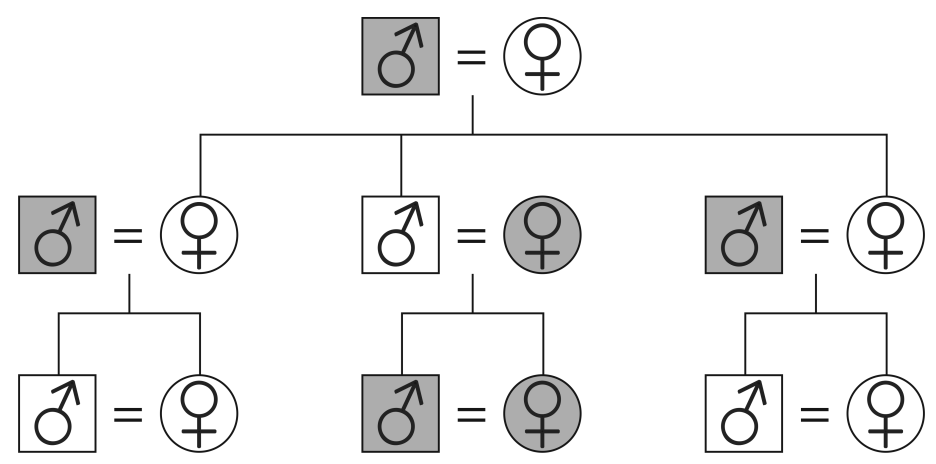

Fig. 7.2 Matrilineal definition of blood relatives

Note: A circle represents a female and a square represents a male. One's lineage consists of all descendants (white) of all common female ancestors through female blood lines. Children of both genders belong to their mother's, but not their father's, lineage. One is thus related to one's mother but not one's father, and to all members of one's mother's lineage but not to members of one's father's lineage.

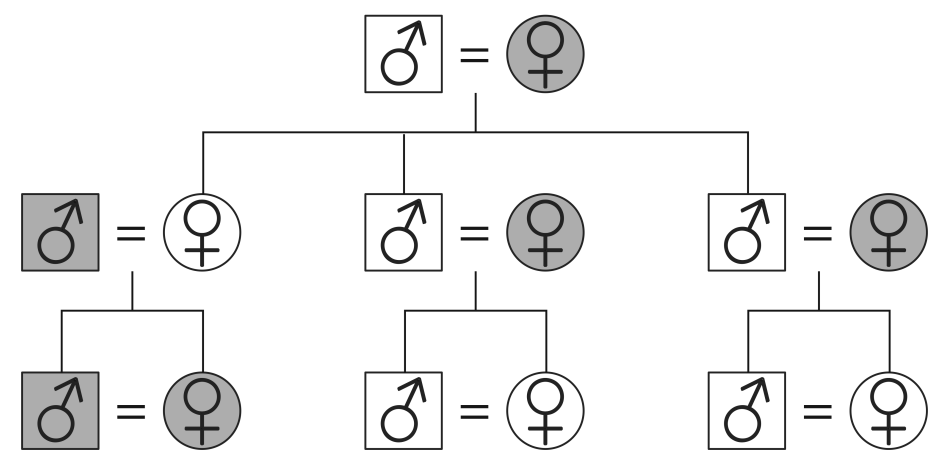

Fig. 7.3 Patrilineal definition of blood relatives

Note: A circle represents a female and a square represents a male. One's lineage includes all descendants (white) of common male ancestors through male blood lines. Children of both genders belong to their father's, but not their mother's, lineage. One is thus related to all members of one's father's lineage, but not to members of one's mother's lineage.

dren as well as one's father, siblings, half siblings by a common father, aunts and uncles, and so on. One's sisters and half sisters by a common father are members of one's lineage, but their children are not. This is because they belong to that sister's or half sister's husband's family. Likewise, one's grandchildren through a son belong to one's family, but grandchildren though a daughter belongs to their father's family, and are thus not one's blood relatives.

In a patrilineal society, children inherit their father's estate and widows thus look to their children for support see Ollennu (1966) for details. Figure 7.3 distinguishes members of a common patriclan (in white) from persons 
normally considered relatives in Western societies (in gray), who do not count as blood relatives in a patrilineal culture.

\subsubsection{Criticisms of Traditional Inheritance Norms}

A key difference between figures 7.2 and 7.3 is that matrilineal cultures do not number a deceased man's widow or children among his blood relatives. Western observers thus often see patrilineal traditions as more supportive of widows and children.

However, patrilineal norms also appear superficially more familiar to Western observers, who may neither understand nor appreciate the support provided by brothers, maternal half brothers, and maternal uncles in matrilineal societies. A widow with a wealthy brother in a matrilineal tribe may be much better off than a widow in a patrilineal tribe whose poor husband left her children a meager estate. Which system better provides for widows and orphans on average is thus an empirical question, and may not even be subject to broad generalization. Some communities might apply a given set of traditional norms with more generosity to widows and children than others.

Publicized cases of impoverished widows and children in matrilineal tribes, buttressed by survey evidence assembled by women's advocacy groups and Christian organizations, repeatedly made the poverty of widows' and their children a public policy issue in the decades subsequent to Ghana's 1957 independence. Widow-headed households throughout Ghana, but most evidently in rural matrilineal homes, were highlighted as having extreme levels of poverty - due in part, at least, to traditional inheritance norms. Intestacy law reform attracted increasing debate, but actual reform was slow to come. One reason for this deadlock was the absence of a viable reform proposal, and another was doubtless the legislators' fear of providing fodder for tribal chauvinists.

The case for reform grew to encompass several arguments. The most direct was the case for conjugal (nuclear) families retaining all or most of a deceased spouse's assets to shield widows and their children from poverty.

But the case for reform went beyond such welfare considerations. Of at least equal importance were the incentives inheritance customs created for wealth accumulation by individuals and conjugal families. Especially in matrilineal tribes, a plausible case was made that the transfer of a conjugal family's assets to the deceased man's maternal nephew undermines the incentives of the husband and wife to acquire skills, exert effort, and accumulate assets, and to blunt the same incentives in maternal nephews.

Another problem concerns the alienability of assets passed to a lineage. No individual person owns these assets, and the conditions under which they can be bought and sold are still murky. A lineage is a corporate entity, but often lacks necessary legal titles because of the difficulties of deeding an asset to multiple owners. For example, throughout Ghana lineages own land and other assets that have no value beyond their primary use. These 
assets cannot serve as collateral for a loan and improvements to them are the property of the lineage, not the individual who pays for the improvements. Individuals thus have scant incentive to add to the value of such assets. Traditional inheritance systems might thus explain, at least in part, the failure of many sub-Saharan countries to formalize titles to land and capital assets (De Soto 2000). Reforms that keep assets from reverting to lineages might ultimately spread clearer property rights and thus improve allocative efficiency.

It is possible to contract around these problems, but lineages must solve a collective action problem to act in concert. Individuals can nullify traditional inheritance norms with a legal will. However, most Ghanaians die intestate. ${ }^{7}$ High illiteracy rates, a lack of access to the formal legal system, and the fear of retaliation by the extended family doubtless all play a role. Males in matrilineal households can attempt to protect their wives and children with intervivos transfers, but these can be undone-either legally or by social pressure.

In fact, actual monetary transfers may also go in the opposite direction: for example, the child pays money to the father. La Ferrara (2006) finds Akan (matrilineal) sons transferring more money to their fathers than do otherwise similar sons in patrilineal cultures, especially if a paternal aunt's son resides with, or lives in the same village, as the father. La Ferrara concludes that the increased transfers from Akan sons are partially attempts to influence their fathers to direct land gifts to them, rather than to the father's nephew.

\subsection{Legal Reforms}

By the mid-1970s, a case for comprehensive reform was widely acknowledged. For example, in 1979, the Constitution of the Third Republic of Ghana proclaimed in its Article 32 (Woodman 1985):

$\$ 2$ No spouse may be deprived of a reasonable provision out of the estate of a spouse, whether the estate be testate or intestate.

$\$ 3$ Parliament shall enact such laws as are necessary to ensure that every child, whether or not born in wedlock, shall be entitled to reasonable provision out of the estate of its parents.

Parliament, of course, did no such thing, and the Constitution was abolished in a military coup later that year. The military junta reiterated the two pledges, but took no immediate judicial or legislative action.

On June 14, 1985, the Provisional National Defence Council (PNDC), the ruling military junta, proclaimed four interrelated reforms that, in theory at least, radically reformed the ground rules for intestate inheritances. These

7. In our survey of widows, only 8 percent reported that their spouse had a legal will. 
were: the Intestate Succession Law (PNDC Law 111, 1985); the Customary Marriage and Divorce (Registration) Law (PNDC Law 112, 1985); the Administration of Estates Law (PNDC Law 113, 1985); and the Head of Family Accountability Law (PNDC Law 114, 1985). All four initiatives were justified in an accompanying memorandum as reflecting "the growing importance of the nuclear family" relative to the extended family.

\subsubsection{The Intestate Succession Law (PNDC Law 111, 1985)}

The most important of these for our purposes, and for rebalancing customary inheritance norms against the needs of surviving members of the conjugal family, is the Intestate Succession Law (PNDC Law 111, 1985) hereinafter Law 111. Indeed, it has been characterized as the most radical legislative reform ever made in the private law of Ghana (Woodman 1985). We therefore pause to elaborate.

Although Law 111 is phrased to be gender neutral, it was seen as a victory for women and so hailed by women advocacy groups. The law allows a widow and her children - hitherto completely denied rights to the nuclear family's assets under matrilineal norms - to be the primary beneficiaries of the deceased husband.

The writ of Law 111 is restricted in two ways. First, the law applies only to property not disposed of in a legal will. Because most Ghanaians die intestate, this restriction is not thought to be of paramount importance. More importantly, Law 111 does not apply to lineage property - a concept unfamiliar to most Western observers. Much land, and other sorts of property too, belongs to a lineage, and not to any individual. Such property assigned to the deceased husband for use during his life automatically reverts to the lineage upon his death, and in a matrilineal tribe most likely passes to one or more of his maternal nephews. ${ }^{8}$ Law 111 does apply only to selfacquired property - assets the deceased, or his nuclear family, purchased or created during his life. Because the husband is typically considered its sole owner, a conjugal family's self-acquired property virtually always reverted to a deceased husband's lineage. A woman's role, in whatever form, was rarely recognized. The lawmakers explicitly referred to this issue in an accompanying memorandum, which explained the reforms thus: "It is the right that

8. Lineage property, which encompasses the extended family-owned assets, is distinct from tribal property. A typical example of tribal property is the communal land "owned," in principle, by the paramount chieftaincy (called the stool) in trust. Individuals have rights to use the land for farming or for some other commercial activity by virtue of membership of the tribe, but only with the consent from the stool (i.e., the chief). Tribal and lineage land are essentially inalienable because of a "tragedy of the anticommons" problem. All members of the currently living generation of the lineage or tribe are considered custodians for property that also belongs to all past and future generations, and thus cannot be sold without the explicit consent of all living lineage members plus countless deceased and unborn generations of the lineage - a condition prospective buyers can be certain is never satisfied. Sagas abound of foreigners thinking they have purchased such property when they have not. 
the husband with whom the woman has lived and whom she has probably served, is the person on whose property she must depend after his death."

Law 111 partitions a decedent's assets into two categories: household chattels and residue assets. Household chattels include all household belongings in regular use: clothes, furniture, appliances, a family noncommercial vehicle, farm equipment, and household livestock. All household chattels automatically devolve to the conjugal family. Residue assets include business-related and investment assets: business properties, commercial vehicles, nonprimary residential properties, bank accounts, savings, and investments. Residue assets are distributed to members of the decedent's conjugal family and extended family according to a set of formulae set forth in sections 5-8 and 11 (Articles 1 and 2) of Law 111. Table 7.1 summarizes these.

The first row of the table sets out a baseline case, where the decedent has surviving relatives in all relevant classes. In this example, section 5 stipulates that three-sixteenths of the residual goes to the spouse, nine-sixteenths to the surviving children, and one-fourth to the lineage, that last to be split equally between the parents and those entitled to inherit under the decedent's traditional norms.

The other rows modify the baseline formula in the absence of surviving heirs of one or more sorts. For example, the second line shows that if the decedent has no living spouse- - because of either a divorce or the spouse's prior death - what would have been the spouse's share passes instead to the children. If the decedent has neither a living spouse nor living children, what would have been their shares passes to the decedent's lineage - with the parents receiving three-fourths of the residue property and the remaining one-fourth distributed by the lineage in accordance with its traditional

Table 7.1

Residue property distribution under Intestate Succession Law (PNDC Law 111, 1985)

\begin{tabular}{lccccc}
\hline & \multicolumn{5}{c}{ Share of residue Law 111 assigns to: } \\
\cline { 2 - 7 } Living conjugal and extended family members & Spouse & Children & Parents & Lineage $^{\mathrm{a}}$ & State $^{\mathrm{b}}$ \\
\hline If all survive & $3 / 16$ & $9 / 16$ & $1 / 8$ & $1 / 8$ & 0 \\
No living spouse & - & $3 / 4$ & $1 / 8$ & $1 / 8$ & 0 \\
No living children & $1 / 2$ & - & $1 / 4$ & $1 / 4$ & 0 \\
No living spouse or children & - & - & $3 / 4$ & $1 / 4$ & 0 \\
No living spouse, children, or parents & - & - & - & 1 & 0 \\
No surviving known relatives & - & - & - & - & 1 \\
\hline
\end{tabular}

Note: The decedent's residue property (property not classified as household chattels or lineage property) is apportioned to relatives by one of the following formulas. Residue assets include business-related and investment assets: business properties, commercial vehicles, nonprimary residential properties, bank accounts, savings, and investments. The applicable formula depends on which of the decedent's relatives survive.

aTo be distributed in accordance with the traditions of the lineage.

bIn trust for any person subsequently identified as sufficiently close to the deceased to be a legitimate heir. 
norms. In the rare event of the decedent having no known relatives of any kind, the residue property goes to the state in trust, and can subsequently be disbursed to one "who was maintained by the intestate or with whom the intestate was closely identified," should such a person be found to exist. Thus, someone who lived with, or was related in some sufficiently close way to, the decedent can seek a court order to inherit a portion or all of the estate (see Woodman 1985).

Over the more than a quarter of a century since Law 111 took effect, anecdotal evidence and reports by women's advocacy and religious groups concur that the law is not widely followed. The most likely reasons for this are a lack of information about the law, the inaccessibility of the formal legal system to many people, and a very real fear of reprisals from the lineage for violating customary laws. Many families, especially in rural areas, know only the customary laws of their tribes. Moreover, government officials in these areas are often reluctant to enforce the formal law and apply sanctions when it is violated because these same officials are often also charged by their traditional communities with upholding customary laws.

The formal law is a written body of knowledge, while customary law is passed along orally, and thus more accessible to illiterate people. If legislation from Accra conflicts with tribal custom, the latter usually wins out. A 2007 study by the Ghana office of the International Federation of Women Lawyers (FIDA 2007) shows about 40 percent of survey respondents interviewed in Accra (the capital and mainly patrilineal), Kumasi (the secondlargest city and predominantly matrilineal), and Koforidua (a mixture of inheritance systems) had either no or an erroneous knowledge of Law 111, with these responses much more frequent among people with little or no education. A mere 3 percent had a complete knowledge of the law. ${ }^{9}$ The FIDA study pursues the issue with the few respondents who knew of the law. Even these find actual use of Law 111 to be restricted by multiple barriers.

Widows often lack the financial resources to mount a legal challenge, and are often overwhelmed and frustrated by a cumbersome legal procedure. The widow must petition for a Letter of Administration from the courts to gain standing - and this requires the approval of the head of the decedent's lineage, typically a contending party. In addition, she must obtain competent legal guidance to execute this document precisely in accordance with the letter of Law 111, for any procedural error nullifies her case. Added to the expense of legal advice is the cost of the decedent's funeral and burial rituals, which the widow must pay in their entirety should she contest the customary law. These costs are easily prohibitive given the importance of

9. Recent education drives and social awareness programs are actively working to inform people of their rights under the formal legal system. Prominent among them are: the Ministry of Women and Children, the Federacion Internacion de Abogadas ([FIDA], known in Ghana as the International Federation of Women Lawyers), the Women's Initiative for SelfEmpowerment (WISE), and Women in Law and Development in Africa (WiLDAF). 
elaborate funerals in Ghanaian cultures. The community typically expects a grand funeral, and this is only financially possible with the support of the decedent's lineage.

Perhaps even more daunting than all of these financial costs are the social costs a widow risks by challenging traditional norms. The repercussions from overtly disregarding deeply rooted tribal custom can be devastating. This messy and divisive process, with all its attendant costs, conflicts, and adverse consequences, can readily be avoided if the decedent left a will. But the FIDA (2007) study reports that women are unlikely to press their husbands to write a will. Indeed, a majority of interviewed widows did not know if their spouses had a will, and never discussed writing a will with him. This response from one respondent, when asked why, captures the general sentiment:

I could never ask [my husband] if he had a will or not. . . . If I asked, he may even think I am planning to kill him so I can take his assets; or accuse me of being a witch or something bad. He may even ask for a divorce.

\subsubsection{Survivors' (Pension) Benefits under the Children's Act 560, 1998}

A second comprehensive reform to Ghanaian inheritance laws developed in stages, and provides a wealth of government data pertaining to middleand high-income Ghanaian households, whose survey participation rates tend to be very low in any event. The Social Security and National Insurance Trust (SSNIT) runs the sole government-sponsored pension annuity program for retirees. Should the contributor die before his accumulated benefits are fully disbursed, 60 percent of the remaining benefits pass to the decedent's children under age eighteen. Each contributor apportioned the remaining 40 percent to one or more chosen heirs. This reflects a sequence of reforms, but primarily the Social Security Act (PNDC Law 247, 1991) and the Children's Act (Act 560, 1998), hereinafter Law 247 and Act 560, respectively.

Law 247 designates the permissible choices open to members of patrilineal versus matrilineal cultures, and is summarized in table 7.2. Thus, Law 247 prohibits a member of a patrilineal culture from listing a sister's son as an heir, and forbids a member of a matrilineal culture from listing a father's father or father's brother as an heir. But in both cases, one has the option of either adhering to the traditional norms of one's lineage or bequeathing benefits to one's conjugal family.

A pension contributor's choice of heirs is confidential, buried in government files, and available to interested parties only after the contributor's death. This theoretically lets one defy customary inheritance norms by bequeathing one's accrued pension wealth to one's conjugal family, not one's lineage, with no one to know until well after one is safely dead.

The social security system dates back (at least) to 1946, when Chapter 


\begin{tabular}{lll}
\hline Decedent's traditional norm & Patrilineal & Matrilineal \\
\hline Mother, father & Allowed & Allowed \\
Husband & Allowed & Allowed \\
Wife, son, daughter & Allowed & Allowed \\
Brother, sister & Allowed & Allowed \\
Father's father & Allowed & Prohibited \\
Mother's mother & Prohibited & Allowed \\
Father's brother & Allowed & Prohibited \\
Mother's brother & Prohibited & Allowed \\
Mother's sister & Prohibited & Allowed \\
Sister's son & Prohibited & Allowed \\
Sister's daughter & Prohibited & Allowed \\
\hline
\end{tabular}

Note: Under Law 247, only certain persons are eligible to be listed as heirs to a deceased beneficiary's SSNIT pension accruals. Different choice sets are offered to members of matrilineal versus patrilineal tribes.

30 of the Pension Ordinance of 1946 provided government pensions for certain public sector employees, a scheme that became known as CAP30. A more general social security system began with the military government of the time, the National Redemption Council, decreeing (NRCD 127, 1972) the expansion of a previous Parliamentary Act 279 to establish a Provident Fund to pay every formal sector worker a lump sum upon retirement. In 1991, another military government, the Provisional National Defence Council proclaimed the Social Security Act (PNDC Law 247, 1991), hereinafter Law 247, under which the Social Security and National Insurance Trust (SSNIT) is made the sole government-sponsored pension system. The system resembles standard Western pension systems in some ways, but deviates markedly from them in others. Our data cover much of the period when Law 247 was in effect. ${ }^{10}$

Like many government pension schemes, the SSNIT is a pay-as-you-go system: formal-sector workers' current contributions fund benefits paid to pensioners. Law 247 requires that all employers contribute 17.5 percent of their base salaries to the fund. This appears as a 5 percent deduction from the employee's monthly pay check, and is matched by a 12.5 percent employer contribution invisible to the employee. Act 766 now allows the self-employed to join the system by making the full 17.5 percent contribution.

Also like many other systems, the SSNIT is a defined benefit system. The minimum annual pension benefit is 50 percent of the average of the contributor's highest three annual salaries earned in the twenty years prior

10. A new National Pensions Act (Act 766) went into effect in January 2010 and expands the scheme under Law 247 to include voluntary contributions from self-employed persons and individuals in the informal sector. Social Security for the informal sector will be administered by the SSNIT Informal Sector Pension Fund. 
to retirement. The benefit rises by 1.5 percent of average of that average for each additional year of work and contributions to the fund. So, theoretically, anyone who retires at age sixty, having contributed for forty years to the fund, merits a pension equal to 80 percent of average earnings in the retiree's three most prosperous years. ${ }^{11}$

The major difference between most other pension systems and the SSNIT it its fixed term: paid-up contributors are entitled to exactly 144 consecutive monthly benefit payments in retirement, no more and no fewer. Under Law 247, an individual becomes entitled to full-pension benefits after contributing to the scheme for 240 months and attaining the age of sixty, the mandatory retirement age. ${ }^{12}$ The retiree then receives a monthly pension for the next twelve years. When the retiree turns seventy-two, the benefit terminates and the retiree must rely on relatives or savings. Individuals may opt out of this default scenario and receive 25 percent of the payments' present value as a lump sum upon retirement, and the other 75 percent as monthly payments over the next twelve years.

If the contributor dies before age seventy-two, the present value of the remaining payments the contributor would have received, computed at the treasury rate over the same period, was then paid to the heirs the contributor chose from the options made available in table 7.2. ${ }^{13}$ The largest subsequent change to this system, the Children's Act (Act 560, 1998) of 1998, mandates that the SSNIT pay 60 percent of such survivor benefits to the contributor's minor children (age eighteen or younger). In theory, whenever the SSNIT receives a procedurally complete claim, with all necessary supporting documents (e.g., death and burial certificates), it should investigate the family to ascertain whether or not the decedent has minor children not listed as beneficiaries. In practice, the SSNIT lacks the resources to do this, and merely ascertains the validity of the submitted claim. The remaining 40 percent of the survivor benefit is then disbursed to the beneficiaries the decedent selected from the appropriate column in table 7.2, in the selected proportions.

Another major difference is that Ghana's government-sponsored pension program was, until very recently, restricted to formal-sector employees. Workers in the informal sector-subsistence agriculture, fishing, roadside stands, and so forth - are not covered. ${ }^{14}$ Some 80 percent of Ghanaians work

11. Early retirement, starting from age fifty-five, with reduced pension payments is permitted under Law 127. Individuals who retire before age sixty lose 7.5 percent of their age sixty retirement benefit for each year until their sixtieth birthday. People in high-risk occupations, such as mining, are exempted and can retire at fifty-five years with full pension.

12. If a contributor falls short of the required 240 months, the total contributions plus interest at half the T-Bill rate is refunded as a lump sum at retirement.

13. Benefits are discounted at the lower of the prevailing Treasury bill rate and ten.

14. Recent reforms (Act 766, 2008) mandate that the SSNIT organize the Informal Sector Social Security Fund, which actively encourages informal-sector workers to sign up and save for their retirement. 
in the informal sector-subsistence agriculture, fishing, roadside stands, petty trading, and the like (Heintz 2005). The SSNIT data thus pertain only to middle- and upper-income Ghanaians. We therefore use both SSNIT data and surveys of inheritance patterns among low-income Ghanaians to gain a broader picture of the current situation.

\subsection{Data and Empirical Strategy}

\subsubsection{Survey Data Descriptive Analysis}

We surveyed 322 widows living in four villages in Southern Ghana: Bortianor and Ingleshi Amanfro are both predominantly patrilineal, and in the Greater Accra Region; Abura Dunkwa and Nyankomase Ahenkro are in the Central Region and most lineages there are matrilineal.

Potential survey participants were identified with the help of a town or village council member, a town leader, or the traditional chief, whose approval was sought for our team of researchers to conduct the survey. Households were randomly chosen, and the questionnaires were administered to an adult person in the house, in private. Because visits to randomly selected, seemingly more affluent households in the urban areas generally yielded no responses, our final data consist mostly of very low-income respondents, though not the poorest of the poor living rough. About 50 percent of our respondents reported no formal education, and 25 percent reported the same for their spouses. The average is five years of formal education. Only 5.2 percent reported a bank account (single or joint), though 26 percent have other personal assets. Nonetheless, over half reported contributing directly to the conjugal family's wealth.

The survey data contain information to assemble a profile of each respondent's age, education level, inheritance system, years married, children (by spouse), minor children, and marriage type (polygynous or monogynous). Our youngest respondent was age twenty and our oldest was age ninetythree. Consistent with the ethnic distribution in Ghana, about 48 percent reported their traditional custom as matrilineal. Respondents also provided information to let us assemble similar profiles of their spouses. Spouses' profiles appear similar, though they are slightly more educated — about eight years of formal education.

A key part of our analysis is to gauge how respondents' information about the law shaped the ownership structure of the family assets (i.e., individually owned or jointly), which law was applied in the distribution of the assets when a spouse died, and the welfare of the family after the death. We therefore asked widows an additional set of questions. Nearly 47 percent report prior knowledge of the law at their marriage or before the death of their spouse, but only 3.2 percent of widows reported its use in their cases. Rather, just over 7.4 percent reported their deceased spouse having a will and over 
75 percent reported the estate having been distributed in accordance with traditional norms. The remaining 14 percent did not know which rule was employed, or reported using a religious-based principle to divide up the estate (e.g., Muslim). Almost 46 percent reported being dissatisfied with the distribution.

To assess widows' economic and social status, we asked respondents to compare their situations in the years immediately before versus after their spouse's death. Because they virtually all dwell entirely in the informal economy, questions about monetary income do not capture their economic situations. We therefore asked them to rate their economic situations or opportunities, defined as access to financial services (formal or informal), health care for themselves and their children, and educational opportunities for their children. Access to financial services in this context means an expectation of being able to borrow money in a pinch from a financial institution, or from the head of the lineage or its more prosperous members. Health care and education typically entail small informal monetary outlays. Thus, obtaining needed medical care and clothing and provisioning children for school require cash outlays that, in a subsistence economy, typically require economic support from one's lineage.

We are also interested in whether or not widows, if they attain better financial situations than traditional law prescribes, encounter tension with their lineages, or those of their husbands. We therefore also ask each widow to compare the quality of her relationships with her spouse's extended family, before versus after his death.

Finally, we are interested in how divergent formal and customary laws affect welfare. We therefore asked widows questions about their economic positions to assess how well their traditional support networks performed. Here, quantitative assessment is tricky. Previous work (e.g., Awusabo-Asare 1990) finds that poor villagers, such as those we interviewed, tend to report their economic situation as very bad, leaving little variation to study. It is therefore necessary to introduce a norm to which they can compare themselves. However, a common norm is inappropriate because different lineages have markedly different capacities to help their less fortunate members. Some lineages include government officials, police, formal-sector workers, émigrés, or others, whose formal or informal income can be redistributed to needy relations. Some lineages belong to tribes with mineral rights, whose revenue streams can also be redistributed from chiefs to lineage heads and then to needy widows. However, most lineages have few or no such resources, and genuinely cannot provide more than minimal subsistence support.

To extricate information about how well traditional lineage support systems function, we asked each widow to consider the financial capacity of the lineage in question to support people such as herself. With this benchmark in mind she was then asked if she received any lineage support, and if so whether this was less than, about in line with, or more than that capacity 
Table 7.3

Marriage patterns: Within versus cross-lineage marriages

\begin{tabular}{llccccc}
\hline & & \multicolumn{3}{c}{ Spouses' traditional lineage } & \\
\cline { 3 - 5 } & & \multicolumn{2}{c}{ Matrilineal } & \multicolumn{2}{c}{ Patrilineal } & Total \\
\hline Respondents' & Matrilineal & 145 & $88.4 \%$ & 19 & $11.6 \%$ & 164 \\
traditional & & $93.5 \%$ & & $11.4 \%$ & & $50.9 \%$ \\
lineage & Patrilineal & 10 & $6.3 \%$ & 148 & $93.7 \%$ & 158 \\
& & $6.5 \%$ & & $88.6 \%$ & & $49.1 \%$ \\
& Total & 155 & $48.1 \%$ & 167 & $51.9 \%$ & 322 \\
\hline
\end{tabular}

Note: Numbers in each cell are numbers of respondents of horizontal lineage classification whose spouses are in vertical lineage classification. Percentages to the right of these numbers are percentages of respondents, percentages below each number are percentages of spouses.

allowed. A study of "mixed marriages," in which one spouse has a patrilineal tradition and another has a matrilineal tradition, would have been especially instructive here. Unfortunately, interlineage marriages within our sample are extremely rare, as shown in table 7.3. Roughly nine in ten Ghanaians marry within their lineage tradition. Studying interlineage marriages would be interesting, but table 7.3 reveals our sample of these to be very small.

Table 7.4 highlights differences in means by respondents' inheritance options. Panel A compares widows who know of Law 111 to respondents who do not, while panel B compares by the deceased spouse's lineage type.

Unsurprisingly, panel A shows that knowledge of Law 111 correlates positively with education for both the respondents and spouses, and the educated are more likely to be in monogamous marriages. Confirming the importance of financial incentives, knowledge of Law 111 is also greater among respondents who report contributing more wealth to their conjugal families. Widows who had knowledge of the law were significantly more likely to have settled their deceased spouse's estate under it. In fact, no one that indicated no knowledge of the law prior to their spouse's death made use of the law in dealing with the estate, suggesting that proponents of the Law's greater usage might consider more energetically distributing information at the time of a spouse's death or serious illness. More surprisingly, though consistently with previous studies such as FIDA (2007), panel A shows that about 70 percent of respondents with a prior knowledge of Law 111 nonetheless settled their deceased spouses' estates in accordance with traditional lineage or religious customs, a figure that is only slightly less than that for respondents with no prior knowledge of Law 111. Presumably, much or all of the estates passed to the lineage in both cases.

Knowledge of the formal law correlates with a better economic situation in widowhood overall. However, it has little traction in explaining the relative economic and emotional support widows receive from their lineages versus those of their husbands. Widows knowledgeable of the law obtain insignificantly better financial support both from their own and spouses' 
A. Mean survey responses by widows' knowledge of Law 111, which extends limited formal legal inheritance rights to conjugal families regardless of customary law

\begin{tabular}{|c|c|c|c|}
\hline & \multicolumn{2}{|c|}{ Knowledge of Law 111} & \multirow[b]{2}{*}{ Difference } \\
\hline & Yes & No & \\
\hline \multicolumn{4}{|l|}{ Respondent profile } \\
\hline Age (years) & 52.9 & 56.6 & $-3.7 * *$ \\
\hline Education (yrs. of formal educ.) & 5.1 & 2.8 & $2.3 * * *$ \\
\hline Monogamy at marriage ( $\%$ of widows) & 82.4 & 65.5 & $16.9^{* * *}$ \\
\hline Monogamy at spouse's death ( $\%$ of widows) & 79.1 & 66.8 & $12.2 * *$ \\
\hline \multicolumn{4}{|l|}{ Information on spouse } \\
\hline Years married & 23.8 & 23.9 & 0.1 \\
\hline Spouse education (yrs. of formal educ.) & 8.0 & 5.5 & $2.5 * * *$ \\
\hline Customary/Islamic marriage (\%) & 82.6 & 85.0 & -2.4 \\
\hline No. of children (with spouse) & 4.6 & 4.8 & -0.2 \\
\hline —age $<18$ (at spouse's death) & 1.8 & 1.9 & -0.1 \\
\hline \multicolumn{4}{|l|}{ Ownership of assets } \\
\hline Joint account $w /$ spouse ( $\%$ of widows) & 4.7 & 5.8 & -1.1 \\
\hline Percent contributed to family assets & 27.6 & 18.4 & $9.2 * * *$ \\
\hline Personal assets ( $\%$ of widows) & 29.7 & 23.8 & 5.9 \\
\hline $\begin{array}{l}\text { Intervivos from spouse: As per ability or } \\
\text { better }(\%)\end{array}$ & 34.2 & 27.1 & $7.1^{*}$ \\
\hline \multicolumn{4}{|l|}{ Distribution of assets } \\
\hline Will (\%) & 12.8 & 2.9 & $9.8^{* * *}$ \\
\hline PNDC Law & 6.1 & 0.6 & $5.5^{* * *}$ \\
\hline Customary/Islamic & 67.1 & 87.3 & $-20.2 * * *$ \\
\hline Percent dissatisfied with distribution & 36.2 & 47.9 & $-11.7 * *$ \\
\hline \multicolumn{4}{|l|}{ Welfare after spouse's death } \\
\hline Economic situation (\% worse off) & 55.7 & 69.9 & $-14.2^{* * *}$ \\
\hline Relationship with in-law (\% worse) & 22.8 & 16.7 & $6.1^{*}$ \\
\hline \multicolumn{4}{|l|}{ Lineage financial support } \\
\hline Own: As per ability or better & 31.5 & 31.2 & 0.3 \\
\hline Spouse's: As per ability or better & 14.1 & 12.1 & 2.0 \\
\hline Difference (own minus spouse's) & $17.4 * * *$ & $19.1 * * *$ & \\
\hline \multicolumn{4}{|l|}{ Lineage emotional support } \\
\hline Own: As per ability or better & 49.7 & 52.6 & -3.9 \\
\hline Spouse's: As per ability or better & 25.5 & 27.2 & -1.7 \\
\hline Difference (own minus spouse's) & $24.2 * * *$ & $25.4^{* * *}$ & \\
\hline
\end{tabular}

B. Mean survey responses by customary law applicable to deceased spouse. The customary law of the deceased husband's lineage determines her inheritance rights

\begin{tabular}{lccc}
\hline & \multicolumn{2}{c}{ Spouse inheritance custom } & \\
\cline { 2 - 2 } & Matrilineal & Patrilineal & Difference \\
\hline Respondent profile & & & \\
$\quad$ Age (years) & 54.6 & 55.1 & 0.5 \\
$\quad$ Education (yrs. of formal educ.) & 5.1 & 2.8 & $2.3^{* * *}$ \\
Monogamy at marriage (\% of widows) & 79.1 & 68.1 & $11.0^{* *}$ \\
Monogamy at spouse's death (\% of widows) & 80.4 & 65.3 & $15.1^{* * *}$ \\
& & & (continued)
\end{tabular}




\begin{tabular}{|c|c|c|c|}
\hline & \multicolumn{2}{|c|}{ Spouse inheritance custom } & \multirow[b]{2}{*}{ Difference } \\
\hline & Matrilineal & Patrilineal & \\
\hline \multicolumn{4}{|l|}{ Information on spouse } \\
\hline Years married & 24.5 & 23.2 & 1.3 \\
\hline Spouse education (yrs. of formal educ.) & 7.5 & 5.8 & $1.7 * * *$ \\
\hline Customary/Islamic marriage (\%) & 85.1 & 82.6 & 2.5 \\
\hline No. of children (with spouse) & 4.2 & 5.3 & -1.1 \\
\hline- age $<18$ (at spouse's death) & 2.1 & 1.6 & $0.5^{* * *}$ \\
\hline \multicolumn{4}{|l|}{ Ownership of assets } \\
\hline Joint account w/spouse ( $\%$ of widows) & 3.9 & 6.6 & -2.7 \\
\hline Percent contributed to family assets & 26.1 & 19.4 & $6.6^{* * *}$ \\
\hline Personal assets ( $\%$ of widows) & 34.4 & 19.3 & $15.1^{* *}$ \\
\hline $\begin{array}{l}\text { Intervivos from spouse: As per ability or } \\
\text { better }(\%)\end{array}$ & 28.4 & 32.3 & -3.9 \\
\hline \multicolumn{4}{|l|}{ Distribution of assets } \\
\hline Will (\%) & 9.7 & 5.4 & $4.3^{*}$ \\
\hline PNDC Law & 5.2 & 1.2 & $4.0^{* *}$ \\
\hline Customary/Islamic & 70.7 & 85.4 & $-14.7^{* * *}$ \\
\hline Percent dissatisfied with distribution & 45.1 & 40.1 & -5.0 \\
\hline \multicolumn{4}{|l|}{ Welfare after spouse's death } \\
\hline Economic situation (\% worse off) & 50.3 & 75.4 & $-25.1 * * *$ \\
\hline Relationship with in-laws (\% worse) & 27.7 & 12.0 & $15.7^{* * *}$ \\
\hline \multicolumn{4}{|l|}{ Lineage financial support } \\
\hline Own: As per ability or better & 31.6 & 31.1 & 0.5 \\
\hline Spouse's: As per ability or better & 13.5 & 12.5 & 1.0 \\
\hline Difference (own minus spouse's) & $18.1^{* * *}$ & $18.6^{* * *}$ & \\
\hline \multicolumn{4}{|l|}{ Lineage emotional support } \\
\hline Own: As per ability or better & 58.1 & 44.9 & $13.2^{* *}$ \\
\hline Spouse's: As per ability or better & 31.0 & 22.2 & $8.8^{*}$ \\
\hline Difference (own minus spouse's) & $27.1^{* * *}$ & $22.7 * * *$ & \\
\hline
\end{tabular}

*** Significant at the 1 percent level.

**Significant at the 5 percent level.

*Significant at the 10 percent level.

lineages than do widows unfamiliar with the formal law. Indeed, widows unfamiliar with the law actually report insignificantly better financial and emotional support from their spouse's lineage, relative to their own. Across the board, widows' own lineages provide more support.

Panel B repeats the exercise, but partitions the data by respondents' spouses' inheritance tradition. Knowledge of the law is substantially greater among widows whose husbands were from a matrilineal tradition, suggesting women's and various organizations have successfully reached more of those that the law was specifically intended to empower. However, panel B also reveals both matrilineal deceased spouses and their widows to be better educated, perhaps also partially explaining their better familiarity with the formal law. Matrilineal spouses' widows are also more likely to have been in monogynous marriages; a situation that presumably improved their im- 
plicit bargaining power with their husband and his family. Matrilineal widows reported having fewer children with their deceased husband, although a slightly larger number of their children were less than eighteen years old at the time she became a widow.

Widows of matrilineal spouses, those least likely to inherit a deceased spouse's assets under customary law, nonetheless report having contributed more to the conjugal family's wealth, and also having accumulated more personal assets. This might explain their small, though insignificantly, greater dissatisfaction with the distribution of those assets after their husbands' deaths.

It seems knowledge of Law 111 mitigates any adverse effects of husbands' matriliny on their widows. Matrilineal men's widows knowledgeable about Law 111 report less dissatisfaction with the distribution of the conjugal family's assets ( 36 percent vs. 48 percent were dissatisfied). Perhaps knowledge of the law strengthens their bargaining power within the traditional inheritance process.

Finally, widows of matrilineal men report insignificantly better financial support both from both their own and their deceased husbands' lineages than do widows of patrilineal men. Widows of matrilineal men also report better emotional support from both lineages. Recall from table 7.4 that 93 percent of matrilineal men's widows are themselves from matrilineal cultures, so strong support from the widow's lineage is unsurprising. But the finding that their deceased husbands' matrilineal lineages also support them, even though their children from such a marriage are not considered theirs, suggests that matrilineal lineages in general provide unexpectedly strong traditional safety nets for widows.

\subsubsection{Pension Bequests Data Descriptive Analysis}

To complement our survey data, which cover very low-income Ghanaians, we utilize official data on individuals' bequest instructions regarding their Social Security and National Insurance Trust (SSNIT) benefits. These data pertain only to Ghanaians with employment in the formal sectorpersons considered to be of middle to high socioeconomic status.

Hardcopy records of each beneficiary's instructions are retained by the SSNIT, and are considered confidential until the contributor's death. Thereafter, the record is opened so that interested parties can learn of their rights, if any, to the deceased contributors remaining benefits. Because of this confidentiality requirement, we were only allowed access to the bequeathal instructions of deceased contributors whose residual pensions had been disbursed, and whose files were closed. Names, addresses, and other information that might identify contributors or their relatives were withheld.

Our total sample of SSNIT data consists of records of 860 contributors who passed away between 1992 (when Law 247 came into effect) and 2006. The median age at death is fifty-four years (mean 52.5 years), which 
is lower than the mandatory retirement age of sixty years. About 70 percent of our contributors were married at death and only 10 percent are women, reflecting the overwhelming predominance of men in the formal sector and a corresponding slighter predominance of women in the far larger informal sector. The data the SSNIT made available also contain more observations from later years. We were told this is because many older files are incomplete, missing much critical information, and less readily accessible.

Summary statistics for the variables we construct from these records are reported in table 7.5. Each record sets out the contributor's pension bequeathal decisions and identifies tribal background, from which we can infer the traditional inheritance custom. Each record also lists the contributor's marital status and most, though not all, provide the average of the

Table 7.5

Summary statistics of pension bequest data

\begin{tabular}{lcccc}
\hline & All & Matrilineal & Patrilineal & $\begin{array}{c}\text { Difference } \\
(t \text {-stat }) \\
(2) \text { minus }(3)\end{array}$ \\
Sample & $(1)$ & $(2)$ & $(3)$ & \\
\hline Age at death & & & & \\
All decedents & $52.5[860]$ & $52.13[421]$ & $52.75[439]$ & $-0.62(0.82)$ \\
Male decedents & $53.12[761]$ & $53.14[357]$ & $53.1[404]$ & $0.02(0.20)$ \\
Female decedents & $47.27[99]$ & $46.56[64]$ & $48.57[35]$ & $-2.01(-0.83)$ \\
Married (fraction) & & & & \\
All decedents & $69.7[600]$ & $69.0[290]$ & $71.0[310]$ & $-2.0(0.55)$ \\
Male decedents & 71.9 & 72.5 & 71.3 & $1.3(-0.39)$ \\
No. heirs listed & & & & \\
All decedents & 2.64 & 2.85 & 2.43 & $0.422(3.25)^{* * *}$ \\
Married decedents & 2.94 & 3.21 & 2.68 & $0.53(3.19)^{* * *}$ \\
Male decedents & 2.67 & 2.96 & 2.41 & $0.55(3.79)^{* * *}$ \\
Married male decedents & $2.96[547]$ & $3.29[259]$ & $2.65[288]$ & $0.64(3.63)^{* * *}$ \\
If claims adjusted by Act 560 ${ }^{\mathrm{a}}$ & $4.91[250]$ & $5.06[123]$ & $4.76[127]$ & $0.30(-1.04)$ \\
Bequest to nuclear family $(\%)$ & & & & \\
All decedents & 58.4 & 59.8 & 57.1 & $2.7(0.85)$ \\
Male decedents & 58.2 & 60.5 & 56.2 & $4.3(1.30)$ \\
Married male decedents & 73.3 & 74.1 & 72.7 & $1.4(0.43)$ \\
Pre-Act 560 decedents & $51.8[348]$ & $55.7[168]$ & $48.2[180]$ & $7.5(1.52)$ \\
Post-Act 560 decedents & $62.9[512]$ & $62.5[253]$ & $0.633[259]$ & $-0.008(-0.21)$ \\
Act 560 audited decedents & 0.547 & 0.564 & 0.530 & $0.034(0.575)$ \\
Benefits paid/claim $(2006 / 07)^{\mathrm{c}}$ & $4,500[85]$ & $5,279[45]$ & $3,622[40]$ & $1,657(-1.38)$ \\
\hline
\end{tabular}

Notes: Means of key variables for all files, files of matrilineal decedents, and files of patrilineal decedents. Numbers in square brackets are sample sizes. Final column contains difference between matrilineal and patrilineal mean, with $t$-statistic for the difference being significantly different from zero in parentheses. ${ }^{\text {a }}$ Length of time (in years) from death of contributor to completion of disbursement of survivor benefits.

${ }^{\mathrm{b}}$ Act 560 , passed in 1998, altered the permissible distribution of survivor benefits.

'In Ghanaian cedis per claim. The exchange rate in 2006/2007 was approximately GH $\not 1=$ US $\$ 1$.

$* * *$ Significance at the 1 percent level.

**Significance at the 5 percent level.

*Significance at the 10 percent level. 
contributor's best three annual incomes from among the twenty years prior to the contributor's death.

The 46.5 percent of contributors reporting tribal affiliations that imply matrilineal inheritance norms aligns well with an estimated 48 percent for the national average. Thus, 46.5 percent of contributors chose from the list of permissible heirs under the matrilineal heading in table 7.2, and the remaining 53.5 percent selected heirs from the list under the patrilineal heading.

Recall from section 7.3 that the purpose of this restriction is to restrict the contributor to leaving residual benefits to the conjugal family or the traditional lineage. Bequests of pension benefits to others-for example, persons not belonging to the conjugal family or traditional lineage-are proscribed. Thus, the SSNIT does not permit a contributor from a patrilineal tribe to list a maternal uncle as an heir. Should a contributor attempt this, the list would be rejected. In private conversations with SSNIT staff, we were told that the SSNIT cannot enforce this rule completely. In practice, a mislabeled maternal uncle might become a heir. The SSNIT officials informed us that they simply lack the resources to thoroughly investigate each list of beneficiaries, and in the absence of a challenge from other relatives and if the claims are procedurally valid, simply distribute remaining funds to the pension recipients' selected beneficiaries without further investigation. The record of each contributor's bequeathal decision lists the chosen beneficiaries, the fraction of the total benefits bequeathed to each, and the relationship of each to the contributor.

Upon the death of a contributor, the SSNIT takes no action. Potential heirs must submit claims for survivors' benefits after a qualified contributor dies. The SSNIT staff informed us in private conversations that substantial benefits go unclaimed because heirs are unaware the benefits exist, and because people who learn they are not listed beneficiaries often fail to inform those who are of their rights. Unsurprisingly, contributors who were married at death list more beneficiaries: 2.94 versus 1.94 for single contributors. Male contributors list more beneficiaries than do female contributors, and contributors from matrilineal tribes list a slightly larger average number of beneficiaries (2.85) than do those from patrilineal tribes (2.43).

Finally, each record provides the total value of survivor benefits paid out. These can be substantial by Ghanaian standards: the median for the 319 records closed in the 2006-2007 fiscal year, when the Ghanaian cedi was at $\mathrm{GH} \phi 1=\mathrm{US} \$ 1$, was $\phi 2,142$; the mean was $\phi 4,500$; and the standard deviation was $\notin 5,539 .{ }^{15}$ The bequests were thus typically four to over seven times more than Ghana's gross domestic product (GDP) per capita, which then stood at only about US $\$ 500$.

Also recall from section 7.2 that the 1998 Children's Act 560 altered the

15. Not all 319 passed in that year; some died earlier, but survivor-benefits were not disbursed until 2006. 
permitted distribution of survivors' benefits by the SSNIT. Prior to this, the contributor's list of beneficiaries determined the distribution of all remaining benefits, but afterward 60 percent of the total benefits must go to the contributor's child(ren) under eighteen years of age, regardless of whether they are listed as beneficiaries or not, and the remaining 40 percent is distributed in accordance with the contributor's list of beneficiaries. The SSNIT theoretically investigates each claim to uncover other minor children, including illegitimate children, though in practice resource constraints limit this. One result of this is an increase in the number of beneficiaries in records closed after 1998 because the SSNIT adds the names of minor children to these. Thus, files closed under Act 560 named an average of 4.91 beneficiaries each, while those closed prior to 1998 named an average of 2.61 beneficiaries each. This Act thus substantially shifted SSNIT survivor benefits away from what contributors initially intended and toward their own children. This proves useful in the econometric analysis below.

\subsection{Methodology and Econometric Results}

We now examine econometrically the impacts of these two reforms. Our goal is to estimate the extent to which tribal inheritance norms shape economic outcomes of those on the margins of Ghanaian society, and for the case of retirees, how the reforms influence private, end-of-life bequest decisions. We begin the analysis with individuals' bequest decisions about their unexpired pensions. Because we are interested in the status of widows, we first focus on the 90 percent of our SSNIT records that are males.

\subsubsection{Pension Bequest Decisions and the Children's Act (Act 560, 1998)}

The 1998 Child Act 560 sought to improve the status of widows and their children by instructing the SSNIT to adjust survivors' benefits so that at least 60 percent of unexpired benefits passes to his minor children, regardless of the contributor's instructions.

Ideally, we would also like to investigate how Act 560 altered contributors' bequest decisions. In 1998, the changes were widely publicized, and contributors were urged to alter their bequests to accord with the new rules. No doubt many contributors ignored this advice, and left their original instructions in place. Unfortunately, our data on closed SSNIT files include too few decedents whose initial instructions are dated after 1998 to allow statistically meaningful analysis. We therefore contrast the recorded bequest decisions of contributors who died after 1999, some of which were changed to reflect the new rules, against the decisions of contributors who died earlier, and who thus felt no pressure to alter their instructions to the SSNIT. We take 1999, rather than 1998, as our transition year to ensure that contributors had sufficient opportunity to react to the rule change. 
To determine whether the new rule altered the number of heirs contributors listed in their SSNIT files, we estimate regressions of the form

$$
\begin{aligned}
\text { No. of heirs }= & X_{i} * \alpha+\beta_{o}{ }^{*} \text { matrilineal }+\beta_{1}{ }^{*} \text { postAct560 } \\
& +\beta_{2}{ }^{*} \text { postAct } 560 * \text { matrilineal }+\beta_{3}{ }^{*} \text { matrilineal } * X_{i} \\
& +\beta_{4}{ }^{*} \ln (\text { age })_{i}+\epsilon,
\end{aligned}
$$

where postAct560 is an indicator variable set to one if the contributor's death occurred after 1999, and zero otherwise; $\log$ (age) is the logarithm of the age at which he died, and the $X_{i}$ are individual characteristics including marital status and an indicator variable for the contributor being among the top 25 percent in total unexpired pension (Top25Pension) in the cohort who died in the same year. We interpret this indicator variable as a proxy for the contributor's total wealth, which is unavailable. Finally, we control for age, the contributor's age at death.

Table 7.6 reports estimated parameters for equation (1). The 2.67 grand mean summarizes a statistically significant increase from a bit over 2.5 heirs per contributor prior to 1999 to just below three thereafter. The typical contributor dying after 1999 thus names more heirs as beneficiaries, regardless of customary law. The positive significant coefficient on $\ln ($ age) indicates that older men also name more heirs in the bequests decisions. While this might be explained by older men having had time to sire larger families,

Table 7.6

Number of heirs listed in SSNIT records

\begin{tabular}{lrlrlrl}
\hline Sample & \multicolumn{2}{c}{ All males } & \multicolumn{2}{c}{ Married males } & \multicolumn{2}{c}{ Married females } \\
\hline Matrilineal & 0.086 & $(0.90)$ & 0.120 & $(1.26)$ & -0.332 & $(-1.46)$ \\
Post-Act 560 & 0.100 & $\left(1.66^{*}\right)$ & 0.098 & $(1.25)$ & -0.577 & $\left(-2.75^{* * *}\right)$ \\
Married & 0.223 & $\left(3.40^{* * *}\right)$ & - & & - & \\
Top 25 & 0.127 & $\left(1.68^{*}\right)$ & 0.158 & $(1.54)$ & -0.967 & $(-0.47)$ \\
Post-Act 560* matrilineal & -0.038 & $(-0.42)$ & 0.087 & $(0.74)$ & 0.240 & $(0.78)$ \\
Married * matrilineal & 0.122 & $(1.25)$ & - & & - & \\
Top 25* matrilineal & 0.017 & $(0.16)$ & 0.433 & $(0.31)$ & -0.009 & $(-0.03)$ \\
log(age at death) & 0.572 & $\left(5.85^{* * *}\right)$ & 0.593 & $\left(4.28^{* * *}\right)$ & 1.034 & $(3.04 * *)$ \\
Intercept & -1.842 & $\left(-5.03^{* * *)}\right.$ & -1.707 & $\left(-3.16^{* * *}\right)$ & -2.686 & $\left(-1.95^{*}\right)$ \\
$R^{2}$ & & 0.13 & & 0.08 & & 0.26 \\
No. of obs. & & 761 & & 547 & 53 \\
\hline
\end{tabular}

Note: Dependent variable is the logarithm of the number of heirs listed by the deceased male contributor to the SSNIT pension system. Reported values are OLS estimates, and numbers in parentheses are $t$-statistics.

$* * *$ Significant at the 1 percent level.

**Significant at the 5 percent level.

*Significant at the 10 percent level. 
it could also be due to older men being more conscientious about their legacies.

We include all male contributor files in the above analysis because many males who declare themselves unmarried nonetheless report children. These may be widowers, men who interpret the question as pertaining only to formally recorded marriages, men with illegitimate children, or the SSNIT may not update this field when updating data about children. Reestimating the regressions using males who report themselves as married in their SSNIT files generates broadly similar results, though the post-Act 560 indicator variable now fails to attain significance in the smaller sample. For completeness, we also estimate the regression for female contributors (not shown) and for married female contributors. Like males, older female contributors have more heirs, but unlike their male coworkers, females list markedly fewer heirs after Act 560 than before it. The very small sample makes this result somewhat uncertain, despite its statistical significance.

Conceding the considerable limitations of our data and methodology, we infer that the data are not inconsistent with a discernable difference between bequest decisions before and after the Act. The purpose of the Act was to induce contributors to provide more fully for their conjugal families and to divert bequests away from their lineages. To quantify its effectiveness, we calculate the total fractions of unexpired pension contributors' bequests passed to different categories of relatives, implicitly assigning zero to unmentioned relations. Again, data limitations necessitate caveats. We need not have complete information about each contributor's family. For example, no children listed as beneficiaries means the contributor made no provisions for children, not that he had none. He may have neglected to update his record as his family grew, or he might have deliberately omitted his children. We partition each contributor's heirs into two groups: conjugal (or nuclear) family — sons, daughters, and surviving spouse(s) - and other lineage members. This partition highlights the difficulties we confront in drawing inferences from these data: only 72 percent of males are classified as married. This is far lower that the married fraction of the male population known from census records, and therefore suggests that many contributors likely do not update their SSNIT records. Because Ghanaian culture exerts huge social pressure on men to father children, most place marriage and raising a family among their highest life priorities. This is particularly so for men in the formal sector, whose economic positions make them highly marriageable.

Finally, every individual, no matter how isolated, belongs to a lineage. The only conceivable exceptions would be orphaned foreigners from outside sub-Saharan Africa who adopt Ghanaian citizenship.

Our regressions explain the fraction of residual benefits each contributor in our sample bequeathed to members of his nuclear family (as opposed to his lineage), which we denote percentNUC, are of the form 
(2)

$$
\begin{aligned}
\text { percentNUC }= & X_{i}^{*} \alpha+\beta_{o}{ }^{*} \text { matrilineal }+\beta_{1}{ }^{*} \text { postAct560 } \\
& +\beta_{2}{ }^{*} \text { postAct560*matrilineal }+\beta_{3}{ }^{*} \text { matrilineal } * X_{i} \\
& +\beta_{4}{ }^{*} \ln (\text { age })+\epsilon,
\end{aligned}
$$

where the right-hand-side variables are defined as in regression (1). Because the dependent variable is bounded by the unit interval, with mass at both endpoints, table 7.7 reports tobit regressions.

Unsurprisingly, married men bequeath more to conjugal families than do men listed as unmarried. Because of the problem of stale records, as mentioned above, we reestimate the tobits restricting the sample to men designated as married. The third column presents results for female contributors. Again, age is significant: older men leave more pension wealth to their nuclear families. As above, this may be because older men have longer to build larger families or because they grow more attached to their conjugal families.

Participants whose deaths occur after the 1999 implementation of Act 560 bequeath 12.7 percent more of their pension wealth to their nuclear families. This too indicates that the Act had an effect: When the law mandated that contributors provide more to their nuclear families, they complied.

In addition, the data show a secular time trend toward increasing pension allocations to nuclear families - perhaps because of an ongoing erosion of traditional values. A time trend also accords with a growing social advocacy

Table 7.7

Fraction of unexpired pension bequeathed to nuclear family members

\begin{tabular}{lcccccc}
\hline Sample & \multicolumn{2}{c}{ All males } & \multicolumn{2}{c}{ Married males } & \multicolumn{2}{c}{ All females } \\
\hline Matrilineal & 0.17 & $(1.97)^{* *}$ & 0.001 & $(0.02)$ & -0.209 & $(-0.88)$ \\
Post-560 & 0.127 & $(2.45)^{* *}$ & 0.098 & $(1.97)^{* *}$ & -0.168 & $(-0.91)$ \\
Married & 0.543 & $(7.71)^{* * *}$ & - & - & 0.353 & $(1.97)^{* *}$ \\
Top 25 & -0.069 & $(-1.15)$ & -0.055 & $(-0.94)$ & -0.215 & $(-1.14)$ \\
Post-560* matrilineal & -0.136 & $(-1.91)^{*}$ & -0.074 & $(-1.09)$ & 0.267 & $(1.18)$ \\
Married * matrilineal & -0.146 & $(-1.77)^{*}$ & - & - & -0.120 & $(-0.58)$ \\
Top 25* matrilineal & 0.034 & $(0.43)$ & 0.018 & $(0.23)$ & 0.296 & $(1.21)$ \\
Log(age at death) & 0.508 & $(5.47)^{* * *}$ & 0.415 & $(4.59)^{* * *}$ & 0.534 & $(2.20)^{* *}$ \\
$R^{2}$ & \multicolumn{2}{c}{0.18} & & 0.04 & & 0.11 \\
Observations & \multicolumn{2}{c}{761} & & 547 & & 99 \\
\hline
\end{tabular}

Note: Marginal effects estimated from tobit regressions explaining fraction of benefits bequeathed to surviving spouse(s) and children, as opposed to lineage. Right-hand-side variables are as in table 7.5. Numbers in parentheses are robust $z$-statistics, adjusted for clustering by age of death. Pseudo $R$-squared may not represent variation explained by dependent variables.

***Significant at the 1 percent level.

**Significant at the 5 percent level.

*Significant at the 10 percent level. 
role for the SSNIT. The SSNIT records office staff (in particular, female staff) shared with us stories about how, over time, they increasingly assertively reminded men of their "responsibilities to their nuclear family," and to provide for their spouses and children when listing heirs in their SSNIT records. A time trend added to the regressions in table 7.7 is significant, but a jump is nonetheless discernible at 1999. We conclude that the Act had an effect.

Intriguingly, the tobits reveal that the Act's major effect was not its intended one: altering bequests by men from matrilineal tribes. These men bequeathed more to their conjugal families before the reform, and did not substantially increase these bequests to conjugal families after 1999. One possible explanation is that men from matrilineal tribes used pension bequests to circumvent their tribal inheritance customs all along. These results appear independent of the magnitude of unexpired benefits. The SSNIT bequest decision was, after all, deliberately held confidential until the contributor's death, and could thus provide privacy from pressure to adhere to the traditional inheritance system. Indeed, the SSNIT was intended, in part at least, to provide a defense to men from matrilineal tribes who wished to provide for their children, but who feared the wrath of traditionally minded relatives.

To further test if values might be genuinely changing, we gauge for married men's generosity toward their nuclear families. We define "generosity" as bequeathing more than the mandatory minimum of 60 percent to his nuclear family. That is, generosity $=1$ if percentNUC $>60$ percent and zero otherwise.

Table 7.8 presents logistic regressions, similar in form to equation (2), but with generosity on the left-hand side. Matrilineal and married males are more "generous" than patrilineal and unmarried males to their children, and all males grow more generous after Act 560. However, again, no discernible difference is evident in the Act's effect on men from matrilineal versus patrilineal backgrounds.

The generosity of female contributors' pension bequeathals is remarkably different. Although both male and female contributors are more "generous" if they report more children, female formal-sector workers are decidedly less generous to their conjugal families if their tribal tradition is matrilineal, and grow even less generous after Act 560 takes effect. Policymakers may wish to consider education programs directed at matrilineal females if further steps to force contributors to provide for their own children are deemed desirable.

Next, we estimate the likelihood that the SSNIT ascertains a decedent's instructions to be in violation of Act 560. Also, in cases where the SSNIT discovers a violation of the Act, we explore the sizes of the adjustments it imposes. ${ }^{16}$

16. The Act gives SSNIT staff a degree of discretion where a violation is discovered. In such cases, the bequests to minor children can be raised to more than the minimum allowed by the Act. 
Table 7.8

Generosity of pension bequests to nuclear family

\begin{tabular}{lrccccc}
\hline Sample & \multicolumn{2}{c}{ All males } & \multicolumn{2}{c}{ Married males } & \multicolumn{2}{c}{ All females } \\
\hline Matrilineal & 0.235 & $(2.30)^{* *}$ & 0.048 & $(0.76)$ & -0.361 & $(-2.04)^{* *}$ \\
Post-560 & 0.118 & $(1.95)^{* *}$ & 0.081 & $(1.47)$ & -0.346 & $(-2.39)^{* *}$ \\
Married & 0.550 & $(10.92)^{* * *}$ & - & - & 0.373 & $(2.09)^{* *}$ \\
Top 25 & 0.035 & $(0.48)$ & 0.024 & $(0.37)$ & -0.278 & $(-1.29)$ \\
Post-560* matrilineal & -0.105 & $(-1.20)$ & -0.025 & $(-0.31)$ & 0.414 & $(2.70)^{* * *}$ \\
Married * matrilineal & -0.133 & $(-1.30)$ & - & - & -0.219 & $(-0.88)$ \\
Top 25* matrilineal & -0.118 & $(-.018)$ & -0.02 & $(-0.02)$ & 0.218 & $(1.16)$ \\
Log(age at death) & 0.558 & $(5.61)$ & 0.427 & $(4.71)^{* * *}$ & 0.523 & $(2.41)^{* *}$ \\
Pseudo $R^{2}$ & \multicolumn{2}{c}{0.22} & & 0.05 & & 0.14 \\
Observations & \multicolumn{2}{c}{761} & & 547 & & 99 \\
\hline
\end{tabular}

Note: Marginal effects are estimated using logit regressions explaining an indicator variable set to one if bequest to surviving spouse(s) and children, as opposed to lineage, exceeds the mandatory minimum required by law for minors (60 percent). Right-hand-side variables are as in table 7.5. Numbers in parentheses are robust $z$-statistics, adjusted for clustering by age of death. Pseudo $R$-squared may not represent variation explained by dependent variables.

***Significant at the 1 percent level.

**Significant at the 5 percent level.

*Significant at the 10 percent level.

We estimate the probability of the SSNIT finding a violation using the following probit regression:

(3)

$$
\begin{aligned}
\operatorname{Pr}(\text { Act560 violated }=1)= & X_{i}^{*} \alpha+\beta_{0}{ }^{*} \text { matrilineal }+\beta_{1}{ }^{*} \text { matrilinea } * X_{i} \\
& +\beta_{2}{ }^{*} \ln (\text { age })_{i}+\epsilon
\end{aligned}
$$

where Act560violated is an indicator variable set to one if the SSNIT decides that the contributor's bequests decision violates Act 560, and to zero otherwise. Table 7.9 reports these results in its first column. The instructions of married decedents are about 19 percent more likely to violate Act 560, but older men are actually less likely to leave instructions that violate the Act. This may well reflect higher odds that older men have only adult children. Finally, high-income matrilineal males are more likely to leave bequests instructions the SSNIT must override.

The second column of table 7.9 reports regressions explaining the magnitudes of the adjustments SSNIT staff make to bequests found to violate Act 560. These regressions have the form

$$
\begin{aligned}
p c t(\text { paid })-p c t(\text { beq })= & X_{i}^{*} \alpha+\beta_{0}{ }^{*} \text { matrilineal }+\beta_{1}{ }^{*} \text { matrilineal } * X_{i} \\
& +\beta_{2}{ }^{*} \ln (\text { age })_{i}+\epsilon,
\end{aligned}
$$

where $[\operatorname{pct}($ paid $)-\operatorname{pct}($ beq $)]$ is the percentage of unexpired pension ultimately paid to the decedent's conjugal family minus the percentage bequeathed. The left-hand-side variable is always nonnegative, but can be zero, 
Table 7.9

Act 560 audits and bequest adjustments

\begin{tabular}{|c|c|c|c|c|}
\hline \multirow{2}{*}{$\frac{\text { Dependent variable }}{\text { Regression type }}$} & \multicolumn{2}{|c|}{$\begin{array}{c}\operatorname{Pr}(\text { Act560 violated }) \\
\text { Probit }\end{array}$} & \multicolumn{2}{|c|}{$\begin{array}{c}\text { Percent paid minus percent } \\
\text { bequeathed to nuclear family } \\
\text { Tobit }\end{array}$} \\
\hline & Marginal effect & t-stat & Marginal effect & $z$-stat \\
\hline Matrilineal & -0.035 & $(-0.04)$ & 1.324 & $(1.71)^{*}$ \\
\hline Married & 0.189 & $(2.34)^{* *}$ & -0.303 & $(-4.46)^{* * *}$ \\
\hline Ln(age at death) & -0.487 & $(-2.76)^{* * *}$ & -0.104 & $(-0.71)$ \\
\hline Top 25 & -0.006 & $(-0.08)$ & 0.0001 & $(0.00)$ \\
\hline Married * matrilineal & 0.010 & $(0.08)$ & 0.066 & $(0.69)$ \\
\hline $\operatorname{Ln}($ age $) *$ matrilineal & 0.002 & $(0.01)$ & -0.393 & $(-1.96)^{* *}$ \\
\hline Top $25 *$ matrilineal & 0.182 & $(1.69)^{*}$ & 0.016 & $(0.18)$ \\
\hline McFadden's $R^{2}$ & \multicolumn{2}{|l|}{0.04} & \multicolumn{2}{|l|}{0.38} \\
\hline Sample & \multicolumn{2}{|c|}{$\begin{array}{c}\text { All male contributors who } \\
\text { died after } 1999\end{array}$} & \multicolumn{2}{|c|}{$\begin{array}{l}\text { All male contributors who } \\
\text { violated Act } 560 \text { rules }\end{array}$} \\
\hline (No. of obs.) & \multicolumn{2}{|c|}{454} & \multicolumn{2}{|c|}{232} \\
\hline
\end{tabular}

Note: The first column is estimated coefficients and $z$-statistics for a probit regression explaining which bequests the SSNIT files ultimately judge in violation of Act 560, which requires 60 percent of residual pension benefits be paid to a decedent's conjugal family if he has one or more minor children at the time of his death. The sample of 454 files includes those of all males who died after 1999, where after the SSNIT gained authority to alter bequests. The second column presents estimated coefficients and $z$-statistics for a tobit regression explaining the adjustments to bequests to nuclear families in the 232 files the SSNIT deemed in violation of Act 560 .

***Significant at the 1 percent level.

**Significant at the 5 percent level.

*Significant at the 10 percent level.

so we employ tobit regressions. Larger adjustments are made to bequests by unmarried, younger matrilineal men.

Our data do not fully clarify their circumstances. One interpretation is that, despite all of the above government policy initiatives and the SSNIT's exhortations, many young men from matrilineal tribes still feel a lesser duty toward their wives' children, or perhaps to their out-of-wedlock children. Alternatively, young matrilineal men might be less attentive to updating their SSNIT files to record marriages and new children. However, we have no a priori reason that they are less attentive than their patrilineal peers. And if they are less attentive, this also suggests less concern about their conjugal families compared to young men from patrilineal tribes.

\subsubsection{Knowledge of Law 111 and Asset Acquisition Decisions}

We now turn from relatively well-off formal-sector Ghanaian men back to our surveys of very poor informal-sector Ghanaian women. Here, we examine the correlation between knowledge of the Intestate Succession Law 
111 and decisions that affect asset accumulation within the marriage, inheritance outcomes, and the economic conditions of widows.

As with the SSNIT files, data limitations prevent cut and dried assessments. We cannot compare responses before and after Law 111 - the law was enacted many decades ago. Moreover, knowledge of the law is almost surely not randomly distributed across women. Social networks among Ghanaians are generally very strong, and a woman may well belong to many social groups - religious organizations, trade groups, and so on. Information about the law is likely disseminated through these groups, so more socially active women are more likely to learn of it. Access to the media-newspapers, radio, and TV - depends on living nearer an urban center, literacy, literate friends or relatives, access to electricity, and other factors that quite plausibly also correlate with widows' economic situations. We can control for education and literacy, but concede the potential importance of left-out variables.

To explore these issues, we estimate regressions of women's knowledge of Law 111 and other factors on her fractional contribution to her nuclear family's assets, whether or not she builds up own assets, and the likelihood of intervivos during marriage. These regressions are of the form

$$
\begin{aligned}
Y_{i} & =\beta_{1}{ }^{*} \text { KnowLaw } 111+\beta_{2}{ }^{*} \text { matri_spouse } \\
& +\beta_{2}{ }^{*} \text { matri_spouse }{ }^{*} \text { KnowLaw } 11+\epsilon
\end{aligned}
$$

where KnowLaw111 is one if the respondent indicates she knew of Law 111 at the time of her husband's death and zero otherwise, educ is her years of formal education, ${ }^{17}$ matri_spouse is one if her deceased husband was from a matrilineal tribe and zero otherwise, and $X$ is a vector of control variables: the husband's education level, the log of their years married, and dummies for the widow's lineage system being matrilineal, their marriage being monogamous, and the widow having minor children at the time of her husband's death.

The dependent variable, $Y_{i}$ in equation (5), is one of the magnitude of intervivos transfers - that is, assets the widow received from her husband before his death; the fraction of the conjugal family's assets she estimates to have been her contribution; and an indicator variable set to one if she had personal assets when her husband died, and to zero otherwise.

To gauge the magnitude of intervivos transfers, widows were asked the following question: "Did you receive financial support from your spouse when he was alive?" The responses were (a) not all, (b) very little, (c) as expected, and (d) very much. To elicit widows' estimates of their proportional con-

17. This variable is zero in many cases, generally low, so the efficiency gain from using the log of one plus years of formal education is small. Using the latter approach yields qualitatively similar results throughout. 
tribution to their conjugal families' assets, we asked them the question: "In your estimation, what percentage of total family assets (since marriage) is your contribution?" Respondents were presented with six choices: (a) zero, (b) less than 20 percent, (c) 20 to 39 percent; (d) 40 to 59 percent, (e) 60 to 79 percent, and (f) 80 percent or more. For whether or not the widow had personal assets that were explicitly her property, as opposed to the property of her husband or a lineage, we asked a simple yes/no question.

Because of the categorical nature of these responses, we employ ordered logit regressions to estimate (5) regressions on the magnitude of intervivos transfers and on the fraction of the conjugal family's assets the widow estimates as her contribution. A probit regression suffices in regressions on her possession of personal assets.

Table 7.10 summarizes the results of these regressions. Respondents who report knowledge of Law 111 also report making significantly higher contributions to their nuclear family's assets, and are significantly more likely to receive intervivo transfers from their spouses. Note that both the widow's education and that of her spouse are included as controls. However, having

Table 7.10

Economic/financial decisions within marriage

\begin{tabular}{lccc}
\hline & $\begin{array}{c}\text { Intervivo } \\
\text { Husband's gifts } \\
\text { to wife while alive }\end{array}$ & $\begin{array}{c}\text { Contribution } \\
\text { Widow's reported } \\
\text { contribution to } \\
\text { conjugal family assets }\end{array}$ & $\begin{array}{c}\text { Personal assets } \\
\text { Widow had personal } \\
\text { assets at husband's } \\
\text { death }\end{array}$ \\
\hline Know law111 & $\mathbf{1 . 2 2 8}^{* * *}$ & $\mathbf{0 . 8 6 1 * *}$ & -0.043 \\
Matrilineal spouse & $(3.76)$ & $(2.44)$ & $(-0.56)$ \\
Know Law $\times$ matrilineal spouse & $\mathbf{0 . 7 7 6}^{*}$ & -0.031 & 0.021 \\
Controls & $(1.92)$ & $(-0.06)$ & $(0.21)$ \\
Regression & $-\mathbf{1 . 6 7 5}^{* * *}$ & -0.204 & 0.081 \\
Sample & $(-3.62)$ & $(-0.44)$ & $(0.75)$ \\
Pseudo $R$-squared & Yes & Yes & Yes \\
\hline
\end{tabular}

Note: Table reports the coefficients of ordered logit regressions explaining the widow's financial situation at the time of her husband's death. The first column summarizes ordered logit regressions explaining approximate fractions of the conjugal family's assets that were intervivo transfers; that is, gifts from husband to wife during his life. The second column summarizes ordered logit regressions explaining the widow's estimate of her approximate fractional contribution to the conjugal family's wealth. The third column summarizes marginal effects in probit regression explaining the widow having acquired personal assets. Robust $z$-statistics are in parentheses. Control variables are: the log of the widow's and spouse's education levels, log of years married, widow's lineage system, whether monogamous marriage, and whether widow had children under age eighteen at the time of spouse's death.

$* * *$ Significant at the 10 percent level.

**Significant at the 5 percent level.

*Significant at the 1 percent level. 
a matrilineal spouse statistically counteracts the intervivo effect entirely, perhaps indicating persistent tendency of matrilineal men to pass wealth to their lineages. Widows with matrilineal spouses contributed insignificantly smaller fractions of their conjugal families' assets, though not significantly less than with a patrilineal spouse.

\subsubsection{The Economic Status of Widows}

Ultimately, the purpose of the reforms we study above is to improve the lot of widows and their children. Our final set of regressions therefore examines the economic outcomes and opportunities for widows in the informal economy. Based on survey responses in the four villages we study, we construct the following dependent variables.

To assess widows' economic status, we asked them to compare their access to financial services (formal or informal), health care, and education for their children in the years immediately after losing their spouse to the years immediately before. For each comparison, respondents were asked to choose between: things got much worse than before the death (quantified as 1), slightly worse (2), the same (2.5), slightly better (3), and much better (4). Each widow's responses to the three questions were averaged, with equal weights, to construct a change in overall economic status.

To assess the efficacy of widows' support from traditional safety nets, we also inquired about the level of financial support they received from their own lineage, and from that of their deceased husband. Their responses to each of these two queries is quantified as follows: no support at all (1); worse support than the lineage's economic situation could readily have allowed (2), a level of support roughly in accordance with what the lineage's economic situation allowed (3), and more support than the lineage's economic situation readily allowed (4).

We control for the widow's "closeness" to each extended family during the marriage by asking how often they "visited or were visited by" members of each lineage. Respondents were asked how often they saw their own or their spouse's family members during the marriage. They were given a choice of four responses: never (quantified as 1); rarely, less than once per year (2); occasionally, about once every six months (3); and very often, at least once a month (4).

Because all three variables are discrete, we run ordered logits to explain them in terms of other responses from our survey. These results are displayed in table 7.11 .

Unsurprisingly, a widow's "closeness" to her own extended family correlates with their providing her greater financial support for her during widowhood. A similar effect is evident for a widow's "closeness" to her deceased husband's extended family, with an almost identical coefficient. Minor children elicit stronger financial support from her own extended family, but not from her husband's lineage. 
Table 7.11

Widows' financial support and changes in economic status

\begin{tabular}{lcccc}
\hline & $\begin{array}{c}\text { Financial } \\
\text { support } \\
\text { from own } \\
\text { lineage }\end{array}$ & $\begin{array}{c}\text { Financial } \\
\text { support from } \\
\text { spouse's } \\
\text { lineage }\end{array}$ & $\begin{array}{c}\text { Change in } \\
\text { economic } \\
\text { status after } \\
\text { widowed }\end{array}$ & $\begin{array}{c}\text { Change in } \\
\text { relationship } \\
\text { with in-laws } \\
\text { (worsening) }\end{array}$ \\
\hline Inherited via Law 111 or a will & 0.016 & -0.0700 & $\mathbf{1 . 0 4 9}^{* * *}$ & $\mathbf{1 . 0 5 3}^{* * *}$ \\
& $(0.05)$ & $(-0.16)$ & $(2.64)$ & $(2.62)$ \\
"Close" to own family & $\mathbf{0 . 3 5 8 * *}$ & 0.115 & 0.091 & -0.120 \\
& $(2.30)$ & $(0.72)$ & $(0.70)$ & $(-0.92)$ \\
Matrilineal lineage & -0.497 & -0.078 & $\mathbf{0 . 5 5 6 *}$ & 0.514 \\
& $(-1.16)$ & $(-0.18)$ & $(1.76)$ & $(1.35)$ \\
"Close" to spouse's family & 0.110 & $\mathbf{0 . 3 2 3} * *$ & -0.064 & $-\mathbf{0 . 2 1 9}$ \\
& $(0.79)$ & $(2.24)$ & $(-0.62)$ & $(-1.96)$ \\
Matrilineal spouse & 0.196 & -0.013 & 0.329 & 0.565 \\
& $(1.92)$ & $(-0.03)$ & $(0.98)$ & $(1.51)$ \\
Child under 18 yrs. & $\mathbf{0 . 6 3 4} * *$ & 0.269 & $-\mathbf{0 . 9 1 3} * * *$ & $-\mathbf{0 . 6 5 4} 4^{* * *}$ \\
& $(2.03)$ & $(0.87)$ & $(-3.85)$ & $(-2.71)$ \\
Education level & 0.004 & -0.047 & $\mathbf{0 . 0 9 1} * * *$ & -0.0001 \\
& $(0.15)$ & $(-1.43)$ & $(2.96)$ & $(0.01)$ \\
Other controls & Yes & Yes & Yes & Yes \\
Sample & 296 & 297 & 295 & 300 \\
$R$-squared & 0.044 & 0.046 & 0.038 & 0.062 \\
\hline
\end{tabular}

Note: Ordered logit regressions explain affirmative survey response to questions about the generosity of financial support from the widow's own lineage (column [1]) and her deceased spouse's lineage (column [2]) after her bereavement, taking into account the overall wealth of the lineage in question as well as the widow's estimate of how her economic status changed, comparing her situation in the years before her husband died to her situation in the two to five years afterward. Control variables not shown are: spouse's education level, log of years married, indicator variables for a monogamous marriage, and whether the widow lived with the spouse.

***Significant at the 1 percent level.

**Significant at the 5 percent level.

*Significant at the 10 percent level.

The third column of table 7.11 shows that a widow's economic status deteriorates less upon the death of her husband if her lineage is matrilineal, but more sharply if she has minor children to support. The first result is somewhat at odds with the presumption of many advocacy groups and government officials that matrilineal widows are less financially secure, though the latter suggests that more could be done to support widows with minor children. We inquired casually about what sorts of support matrilineal lineages provided, and were told of brothers' foster parenting their nieces and nephews, and of the lineage overall providing economic situations widows deemed more appropriate. The last column in table 7.11 sheds some light on how legal reforms, well intended as they may be, can lead to tensions between a spouse or widow and her in-laws. While the results show that widows with closer ties to the in-laws during marriage and those raising younger children 
tend to experience improved relationship with the spouse's lineage members after his death, the use of legal structures to inherit assets (e.g., will or Law 111) leads to a worsening relationship with the in-laws.

Advocacy groups can, however, clearly take heart from the significant coefficient in the first row of the third column. The very few widows - about 11 percent of the sample for this regression - who either made use of Law 111 or inherited under a will report a significantly better shift in economic status around their husbands' deaths. The coefficient is economically large: almost twice that associated with a widow being of matrilineal lineage. Finally, all else equal, widows are substantially better off if they are educated.

\subsection{Conclusions}

Traditional Ghanaian cultural norms, especially regarding customary inheritance rules, differ starkly across tribes and from familiar Western and Asian norms. Reformers saw some of these traditions deterring wealth accumulation among the country's poorest citizens, and impoverishing widows and their children.

These concerns were most voluble regarding the traditions of matrilineal tribes, in which men considered their sisters' children, not their wives' children, to be their nearest relatives in the next generation. These traditions were thought to leave widows and their children economically vulnerable. This latter result seems consistent with that traditionalist argument that brothers and other members of matrilineal lineages support widows, including foster parenting the widow's children. Matrilineal traditionalists countered that their customs held brothers, maternal uncles, and the like accountable for supporting their widowed female relatives, and that this system works well.

Ghana's governments has enacted two major legal rules designed to nudge men of all tribal traditions toward making decisions that would better protect their own children, thus bringing Ghanaians into closer accord with global cultural norms. First, the 1986 Intestate Succession Law 111 changed the rules for dividing up the estate of individuals who die intestate. This reform lets widows file formal legal procedures to secure ownership of certain classes' the conjugal family's assets, and was a major departure from customary rules that assigned most assets to the decedent's lineage (extended family) which, if the deceased belonged to a matrilineal tribe, does not include his widow and children.

Our extensive survey of widows living in matrilineal and patrilineal traditional village societies shows that Law 111 is little used, even by women familiar with it. Law 111 is procedurally touchy, necessitating expensive legal representation that makes its use expensive beyond the means of people in the traditional economy. Its use also overtly challenges traditional law, a sensitive course of action for anyone who must reside in the traditional culture 
for the rest of her life. Those few widows who do use Law 111 are financially more secure, and evidence that they bear social costs is unpersuasive.

Our survey evidence finds matrilineal widows to be more financially secure than patrilineal widows. This supports the position of matrilineal traditionalists that brothers, uncles, and other matrilineal lineage members support widows financially, acting as de facto foster parents for her children.

However, our survey also supports the efforts of reformers. Widows who used the formal legal system to settle their husbands' estates-either by executing a formal will or by applying Law 111 - gain almost twice the financial advantage associated with a matrilineal custom. Further, we find evidence consistent with mere knowledge of the law providing an incentive for couples to build up family assets jointly, and to motivate intervivo transfers from husband to wife, irrespective of education level. But surprisingly, this is least evident among widows whose spouses have a matrilineal lineage tradition - the very people the reforms focused on advancing.

These findings are consistent with knowledge of the law encouraging people to accumulate wealth. However, we cannot preclude the possibility that people who have accumulated assets are more concerned about losing them and therefore seek information about the law regarding inheritances.

The survey data also show that lineages remain an important safety net. Widows who had close ties with their own relatives obtain more financial support from their lineages, and widows who had closer ties with their in-laws likewise report more financial support from his lineage. While formal legal rights might give widows more bargaining power, their scant usage suggests major obstacles impede access to the law for the villagers we survey.

The second major reform we examine is the 1998 Children's Act 560, mandating that the Social Security and National Insurance Trust (SSNIT), the sole pension administrator, allocate 60 percent of deceased contributors' unexpired pensions to their minor children, regardless of their written instructions. The SSNIT reform affects only the estates of Ghanaians who worked in the formal sector and thus contributed to the pension system, while Law 111 sought to affect widows living at the margins of the Ghanaian economy.

Regression analysis of SSNIT records is somewhat problematic. First, we could only access closed files - those in which all bequests had been fully paid out. As many files remain open because the beneficiaries are unaware of their rights, our data suffer from unknown sample selection problems. Second, conversations with SSNIT staff and management indicate that many contributors' bequest instructions were made when they first filled out a SSNIT membership form and never updated. This "stale data" problem weighs against our finding significant effects of the legal reforms affecting SSNIT survivors' pension rights.

Nonetheless, we find some limited evidence consistent with the reforms benefiting decedents' nuclear families. Males who died after Act 560 was 
implemented allocate more of their pensions to the nuclear families; indeed, they bequeath significantly more than the mandatory 60 percent minimum prescribed by the law. Also, when the SSNIT judges a bequest decision to violate Act 560, the adjustments it imposes are overtly favorable to nuclear families, especially those of decedents with matrilineal lineage traditions.

While our analysis finds some evidence of successful reform, we feel their deeper message is a confirmation of the tenacity of African cultural traditions. Formal legislation adopted in Accra does not change the social, economic, and spiritual forces that constrain people's decisions. Genuinely effective reforms appear to require intense efforts to promote social awareness and provide legal aid for those who would exercise their rights under the reforms, and even then can achieve only qualified success.

Our findings complement recent work by Scholz and Gomez (2004). Their examination of formal-sector inheritance rights in Botswana, Ethiopia, Ghana, Nigeria, Rwanda, Senegal, South Africa, Swaziland, Zambia, and Zimbabwe leads them to conclude that traditional inheritance norms prevail regardless of the paper law. Our findings suggest that the absence of resources to exercise formal legal rights may well be more important than a lack of information about those rights. Absent formal social assistance or legal aid programs - which are tenuous to nonexistent in all of these countries - poor Africans rationally conclude that the economic security, however minimal, offered by one's lineage is too valuable to sacrifice for uncertain, inaccessible, and often effectively unenforceable formal legal rights.

If African governments wish to effect reforms to inheritance customs, their formal legal reforms need bolstering by awareness campaigns, meaningful rule of law, and a sensitivity to existing traditions. However, challenges to long-standing traditions are likely to meet sustained resistance in Africa, as in Asia and in the Western world. Our findings also suggest that governments seeking to counter cultural norms thought to deter development might consider designing formal legal rights to empower people within the context of their traditional cultures. Matrilineal widows' economic welfare may well have been improved by the fact that they could challenge traditional inheritance norms, even if few actually did. The law sounds hollow without an accompanying "highlife" drumbeat.

\section{References}

Alger, Ingela, and Jorgen Weibull. 2008. "Family Ties, Incentives and Development: A Model of Coerced Altruism." In Arguments for a Better World: Essays in Honor of Amartya Sen Volume II: Society, Institutions, and Development, edited by K. Basu and R. Kanbur. Oxford: Oxford University Press.

. 2010. "Kinship, Incentives and Evolution." American Economic Review 100:1725-58. 
Awusabo-Asare, K. 1990. "Matriliny and the New Intestate Succession Law of Ghana." Canadian Journal of African Studies 24 (11): 1-16.

Bertrand, Marianne, Sendhil Mullainathan, and Douglas Miller. 2003. "Public Policy and Extended Families: Evidence from South Africa." World Bank Economic Review 17 (1): 27-50.

Bleeker, S. 1966. The Ashanti of Ghana. London: Dennis Dobson.

Chiteji, N. S., and Darrick Hamilton. 2002. "Family Connections and the BlackWhite Wealth Gap among Middle-Class Families." Review of Black Political Economy 30 (1): 9-27.

De Soto, Hernando. 2000. The Mystery of Capital: Why Capitalism Triumphs in the West and Fails Everywhere Else. New York: Basic Books.

Ellul, Andrew, Marco Pagano, and Fausto Panunzi. 2010. "Inheritance and Investment in Family Firms." American Economic Review 100:2414-50.

Fenrich, Jeanmarie, and Tracy E. Higgins. 2001. "Promise Unfulfilled: Law, Culture, and Women's Inheritance Rights in Ghana." Fordham International Law Journal 25:259-341. http://ir.lawnet.fordham.edu/ilj/vol25/iss2/1.

FIDA. 2007. "The Impact of Intestate Succession Law on Women's Inheritance: Accra, Kumasi, and Koforidua." Research Report, International Federation of Women's Lawyers.

Hacker, Daphna. 2010." "The Gendered Dimensions of Inheritance: Empirical Food for Legal Thought.” Journal of Empirical Legal Studies 7 (2): 322-54.

Heintz, James. 2005. "Women, Work, and Poverty in Ghana." Presented at the conference on the Informal Economy in Ghana: A Comparative Perspective, co-hosted by the Ghana Statistical Service and Women in Informal Employment: Globalizing and Organizing, and held at La Palm Royal Beach Hotel, Accra, Ghana, October 24.

Hoff, Karla, and Arijit Sen. 2006. "The Kin System as a Poverty Trap.” In Poverty Traps, edited by Samuel Bowles, Steven N. Durlauf, and Karla Hoff. Princeton, NJ: Princeton University Press.

Kludze, A. K. P. 1983. "Property Law and Rural Development in Ghana." Rural Africana 17:57-67.

La Ferrara, Eliana. 2006. "Descent Rules and Strategic Transfers: Evidence from Matrilineal Groups in Ghana." Journal of Development Economics 83:280-301.

Lastarria-Cornhiel, S. 1977. "Impact of Privatization on Gender and Property Rights in Africa." World Development 25 (8): 1317-33.

Ollennu, N. A. 1966. The Law of Testate and Intestate Succession in Ghana. London: Sweet and Maxwell.

Plateau, Jean-Phillipe. 1991. "Traditional Systems of Social Security and Hunger Insurance." In Social Security in Developing Countries, edited by E. Ahmad, J. Dreze, J. Hills, and A. Sen, 112-70. Oxford: Clarendon Press.

Quisumbing, A., and K. Otsuka. 2001. "Land Inheritance and Schooling in Matrilineal Societies: Evidence from Sumatra." World Development 29 (12): 2093-2110.

Quisumbing, Agnes R., Ellen Payongayong, J. B. Aidoo, and Keijiro Otsuka. 2001. "Women's Land Rights in the Transition to Individualized Ownership: Implications for the Management of Tree Resources in Western Ghana." Economic Development and Cultural Change 50 (1): 157-82.

Scholz, Birte, and Mayra Gomez. 2004. Bring Equality Home: Promoting and Protecting the Inheritance Rights of Women. Geneva: The Centre on Housing Rights and Evictions (COHRE) Series on Law and Practicing in Sub-Saharan Africa.

Woodman, Gordon R. 1985. "Ghana Reforms the Law of Intestate Succession." Journal of African Law 29 (2): 118-28. 